medullary cells but not in other cells of the plant. Cell wall material appears to be of modified cellulose of uncertain character.
Departaent of Brology, McMurry Col.Jegr, Aminenr, Truas

LITERATURE CITED

BАнвен, C. A. 1889. On the structure and development of Laminaria bulbosa. Annals Bot. 3: 41-65.

Fryt, T. C. 1918. 'The age of Pterygophora. Puget Sound Mar. Sta. Pub. 2: 65-69.

Hunpuney, J. E. 1887. On the anatomy and development of Ayarum Turneri. Proc. Amer. Acad. Sci. 2:2: 195-205.

Karker, Joanne. 1916. Micrometabolism in Nereocystis. Puget Sound Mar. Sta. Pub. 1: 227-233.

Knne, Alice L. 1915. Some points in the structure of Alaria fistulosa. Puget Sound Mar. Sta. Pub. 1: 43-57.

Orrver, W. A. 1887. On the obliteration of sieve tubes in the Laminariaceae. Annals Bot. 1: 95-116.

Ormmins, F. 1904. Morphologie und Biologie der Algen. Pp. 1-703. Jena.

Reiskf, J. 1876. Beitrage zur Kenntnis der Tange. Pringsh. Jahrb. Wiss. Bot. Bd. X: 317-382.
RigG, G. B. 19:5. Some physiology of the sieve tubes of Nereocystis. Publ. Puget Sound Biol. Sta. 3: 311329.

Rosenthal, O. 1890. Zur Kenntnis von Macrocystis und Thallassiophyllum. Flora 73: 105-147.

Setchels, W. A. 1891. Concerning the life history of Sacchoriza dermatodea. Proc. Amer. Acad. Sci. 26: 177-217.

Sykes, M. G. 1908. Anatomy and histology of Macrocystis pyrifera and Laminaria saccharina. Annals Bot. 22: 291-325.

'Tummann, Opro. 1913. Pflanzenmikrochemie. Berlin.

WrL., H. 1884. Zur Anatomie von Macrocystis luxurians Hook. et fil. Harvey. Vorl. Mitt. Bot. Zeit. 40: 801$808 ; 825-830$.

Wille, N. 1885. Siebhyphen bei den Algen. Ber. Deutsch. Bot. Ges. $3: 29-31$.

—_ 1897. Beitrage zur Physiologischen Anatomie der Laminariaceen. Det. Kgl. Norske. Frederick's Univ., Program 2det Semester.

\title{
NUCLEAR STRUCTURE AND BEHAVIOR IN SPECIES OF THE UREDINALES ${ }^{1}$
}

\author{
D. B. O. Savile
}

Anyone who studies the illustrations accompanying the many papers dealing with the cytology of the rust fungi must be impressed by two features common to all of them. The first of these is the remarkable variation, both in size and in appearance, of the rust nucleus in different organs and in different parts of the life-cycle. Very little comment is to be found concerning this variability. The second surprising feature is the remarkable dearth of convincing division figures elsewhere than in the basidium. In most stages no figures except a few telophases are to be found, and the interpretation of some of these is questionable.

It seemed to the writer that an elucidation of the nuclear structure and behavior throughout the lifecycle might greatly help our understanding of the general biology of the rusts and also clarify the imperfectly understood diploidization process. An attempt lias accordingly been made to interpret nuclear behavior in the group as a whole, employing a number of species for study, rather than to elucidate what might prove to be the peculiarities of a single species.

A start was made on the investigation under the direction of Prof. J. G. Coulson, in the Department of Plant Pathology, Macdonald College, McGill University, during the winter of 1935-1936, at which time the writer held a Macdonald Alumni Scholarship. The bulk of the work was done at the Univer-

${ }^{1}$ Received for publication April 21, 1939.

Papers from the Department of Botany of the University' of Michigan, No. 693. sity of Michigan, under the direction of Prof. E. B. Mains, during the winters of 1937-1938 and 19381939 ; during this period the writer held the Emma J. Cole Fellowship in Botany. The writer takes this opportunity to express his sincere gratitude for the support that has made the investigation possible.

The writer is deeply grateful to Prof. H. J. Brodie, of the University of Manitoba and formerly of Macdonald College, and to Prof. B. M. Davis and Prof. W. R. Taylor, of the University of Michigan, for their valuable interest and advice throughout the work. Thanks are also due to the many others who have given advice at various times.

Historical survey. - Cytological investigation of the rusts extends back to the work of Schmitz (1880), who discovered conjugate nuclei in the mycelium and urediniospores of Coleosporium Campanulae. The first extensive and important work in this field, however, did not appear until Sappin-Trouffy (1896) described and illustrated nuclear division in a number of species. This paper is of great importance because it indicated the fusion of the paired nuclei and the subsequent reduction division in the teliospore.

The progress in this field of investigation may be divided into three periods. In the first, started by Sappin-Trouffy, the nuclear fusion in the teliospore was stressed, and the origin of the dikaryon was overlooked. Sappin-'Trouffy's work was followed by similar studies by Juel (1898) and Holden and Harper (1903). 
The second period started when Blackman (1904) described the initiation of the dikaryon at the base of the aecial primordium of Phragmidium violaceum by the migration of the nucleus of one cell into an adjacent one through a narrow pore. Shortly after this announcement Christman (1905) reported a slightly different method of diploidization in Phragmidium speciosum; namely, the fusion of two adjacent cells into a single large binucleate cell that gave rise to the aeciospore chain. These findings stimulated great interest in rust cytology, and during the next twenty years the aecial stages of some forty species were examined by Olive (1908), Kursanov (1910, 1922), Fromme (1914), and Lindfors (1924), to name the most important investigators. Nuclear migration was reported in a few species, equal-cell fusion in the majority, and both methods were seen in a number of species distributed through several genera. There was considerable disagreement concerning the relative significance of the two methods. Christman, Fromme, Kursanov (1910), and Olive all considered the few cases of nuclear migration seen by them to be pathological ; but Blackman (1904), Blackman and Fraser (1906), Welsford (1915), and Kursanov (1922) all described nuclear migration through a small pore unaccompanied by equal-cell fusion. Opinion also differed during this period concerning the nature of the sexual process and its bearing on the phylogeny of the Uredinales. All the theories advanced were founded upon the assumption that the pycniospores were functionless.

The discovery by Craigie (1927a, 1927b) that the pycniospores of Puccinia Helianthi and P. graminis are indeed functional ushered in the third period of rust cytology and immediately diverted the attention of uredinologists into new channels. He showed that aecia were produced when the pycnial nectar of different pustules was mixed and spores thereby transferred; but that when this was not done and insects, which serve to transfer the spores in nature, were excluded, the pustules remained sterile. Papers by Craigie (1928, 1933), Hanna (1929), Allen (1930, 1931, 1932, 1933a, 1933c, 1934a, 1934b), Brown (1932, 1935), and I amb (1935) clearly indicate that we may expect most of those rusts the pyenia of which are well developed to prove heterothallic. Ashworth's (1931) study of Puccinia Malvacearum gives weight to the belief that those forms with pycnia rudimentary or absent are homothallic.

Since the function of the pycniospores became known, various attempts have been made to demonstrate the mechanism whereby the pycniospore nuclei are transferred to the cells that they are to diploidize in the aecial primordium. Hanna (1929) suggested that the pycniospores of Puccinia graminis send germ-tubes down through the ostiole of the pycnium to which they have been transferred and form an independent mycelium the cells of which fuse with those of the aecial primordium. Allen (1934a) maintained the same to be true for Melampsora Lini.
Craigie (1933) demonstrated the fusion of pycniospores of Puccinia Helianthi with flexuous hyphae that emerge from the ostioles of the pycnia. These hyphae are distinguished from the stiff, tapering paraphyses by being blunt, flexuous, and very variable in length and abundance. Recently Buller (1938) has described the same process for Puccinia graminis.

Andrus (1931) saw what he termed trichogyne tips emerging from the stomata of bean leaves infected by Uromyces appendiculatus but presented no conclusive evidence that the pycniospores fused with them or that they led directly to the aecial primordium. Rice (1933) reported similar hyphae in the stomata of Oxalis leaves infected by Puccinia Sorghi and considered them to be trichogynes.

Lamb (1935), working with Puccinia Phragmitis, reported the fusion of pycniospores with ostiolar hyphae but could not distinguish the two distinct types described by Craigie. His illustrations, however, do show that some of the hyphae were fairly blunt at the tips, and it is possible that the flexuous hyphae were not well developed. He considered the passage of pycniospore nuclei from the ostiolar hyphae to the primordia, through the existing mycelium, to be the only method of diploidization by the pycniospores; but he noted that the coalescence of pustules of opposite strains also brought about the production of aeciospores. The latter method was demonstrated by Brown (1935) for P. Helianthi after he had already (1932) shown that diploidization could be effected in this way by a diploid pustule.

Allen, working with Puccinia triticina (1931) and $P$. coronata (1932), described hyphae that push out not only through the stomata but between the epidermal cells close to the pycnia. She believed that the pycniospores fused with these hyphae and diploidized the small clusters of cells immediately beneath them. From these clusters the sporophyte was thought to spread to the aecial primordium both by the growth of these diploid hyphae and by the division and migration of nuclei through the existing mycelium.

Lamb's paper provides such an exhaustive discussion of the problem of sexuality in the rust fungi that to deal fully with the subject here could serve no useful purpose. He regarded the evidence for the presence of female sex organs to be very unconvincing and concluded that it was safest to avoid the use of the terms "male" and "female" and to regard the pycniospores as having a syngamic rather than a sexual function; that is to say, they are to be considered comparable to the oidia of the Hymenomycetes, the function of which was demonstrated by Brodie $(1931,1936)$. His view point is thus in contrast with that of Andrus and Rice, each of whom regarded the rusts as having both true spermogonia and trichogynes. Andrus also spoke of the basal cells in the aecium as egg cells.

Materials and methods.-The following rusts have been included in the study: Uromyces Fabae 
(Pers.) de Bary, U. Lespedezae-procumbentis (Schw.) Curt., U. Hyperici (Spreng.) Curt., Puccinia Sorghi Schw., P. Malvacearum Bert., P. Hieracii (Schum.) Mart., Melampsora Bigeloreii Thüm., and Tranzschelia fusca (Pers.) Diet.

Uromyces Fabae, U. Lespedezae-procumbentis, and Puccinia Sorghi supplied most of the material for the aecial stage: the first from field collections and the others from greenhouse cultures with controlled mixing of the pycnial nectar. The teliospore germination stages were studied mainly from $P u c-$ cinia Malvacearum, Melampsora Bigelozeii, and Uromyces Lespedezae-procumbentis.

$A$ wide variety of fixing and staining methods was tried, but the bulk of the material was handled by a few methods found suitable for the purpose.

In the descriptions of the figures the staining and fixing methods are given, in abbreviated form, except where no cytological detail is recorded. The abbreviations used are those given below.

The most generally used fixing solution was formalin-acetic-alcohol (F. A. A.: formaldehyde $[40$ per cent ], 7 cc.; glacial acetic acid, 7 cc.; 50 per cent alcohol, 100 cc.). Somewhat different proportions were occasionally used, but this proved most generally useful, particularly where prompt embedding was not possible.

Chrom-acetic solution (Chr. Ac.: chromic anhydride, 0.5 g.; glacial acetic acid, 3 cc.; water, 100 cc.) was found useful with Heidenhain's haematoxylin for demonstrating certain details.

Duggar's (1909) modification of Gilson's fluid (D. G.) was used extensively because it is very suitable for material stained by the Feulgen method.

Two other solutions were used to a lesser extentnamely, acetic-alcohol (A. A.: glacial acetic acid, 20 cc. ; 95 per cent alcohol, 80 cc.) and formalin-aceticdioxan (F. A. D.: formaldehyde [40 per cent], 7 cc.; glacial acetic acid, 7 cc.; 50 per cent dioxan, 100 cc.).

While the appearance of the fixed nuclear structures was essentially similar after all fixations, the staining reactions of the differently fixed material varied greatly with certain staining methods.

It was soon realized that the usual methods alone would not allow the complete solution of the problem, and an attempt was made to find methods that would supplement or replace them. While no one method was found to be universally applicable, two were discovered that, in conjunction with the generally used Heidenhain's haematoxylin schedule, cleared up most of the difficulties.

The first of these was based on the method described by Naylor (1926), but different dyes and a different buffer series were used. The buffer used was Mcllvaine's disodium-phosphate citric-acid series, cited by Clark (1922). Sections of material fixed in F. A. A. were transferred from water to 0.5 per cent aqueous erythrosin for twenty minutes, dipped in water, and stained for twenty minutes in aqueous methylene blue. After a brief rinsing in water, they were transferred to a buffer solution di- luted 1:50 from stock, at about $\mathrm{pH}+.5$, and left for about three hours. The buffer solution was changed twice during this period. Finally the slides were quickly rinsed in distilled water, dehydrated rapidly to avoid undue loss of dye, and mounted in xylol-balsam. Since the staining results are not markedly different over a range from about $\mathrm{pH} 4.0$ to 5.0, elaborate precautions need not be taken in preparing the solutions. The stock solutions are most easily kept free from molds by covering them with a film of toluene. As might be expected, the reticulum of the host nucleus stains blue in contrast to red nucleoli and chloroplasts and red or purple cytoplasm. The rust nucleus, however, in most stages stains a bright red in strong contrast to the deep blue cytoplasm. As will be shown later, this surprising reaction seems to be due to the staining of ergastic material, perhaps mainly simple proteins, rather than the chromatin in the nuclei of the parasite. The writer has not had the opportunity to test the buffered methylene-blue eosinate method of Lillie and Pasternack (1936), which only recently came to his notice, but it would probably give results somewhat similar to this method. Several samples of each dye were used without apparent difference in the results. This method will be referred to as buffer staining, abbreviated in the description of figures to "buffer."

The second important method, new to rust investigations as far as the writer is aware, is the application of the Feulgen stain. The staining solution was prepared according to the formulae of both Margolena (1932) and de Tomasi (1936), but it was not possible to distinguish between the results. A single sample of basic fuchsin, unfortunately of unknown origin, was used throughout. The solutions kept perfectly. This method is not to be regarded as universally applicable, but it is extremely useful in studying the pycnial stage, in determining the precise distribution of chromatin within the nucleus, and in elucidating the nuclear divisions in the aecium. As the aeciospores, urediniospores, and teliospores approach maturity, some substance giving a red tinge to the cytoplasm is often present; the color is not identical with that of the chromatin, being a true red rather than purple, but it is close enough to it to hinder observation, particularly when the chromatin is finely dispersed. The method, therefore, is often disappointing for these stages, though good preparations are sometimes obtained. All fixing fluids except the chrom-acetic proved satisfactory with this method. It proved uniformly disappointing with all rusts and all host plants examined. Even with a long hydrolysis, which tends to loosen the sections from the slide, it was never possible to get more than a dull nuclear stain. The staining schedule used was that given by de Tomasi, fast green F. C. F. being used as a counterstain. This counterstain is to be understood in all cases, though the method will be referred to simply as Feulgen staining.

When the disposition of the chromatin is discussed, it is to be understood that by "chromatin" is meant the material, presumably nucleoprotein, that 


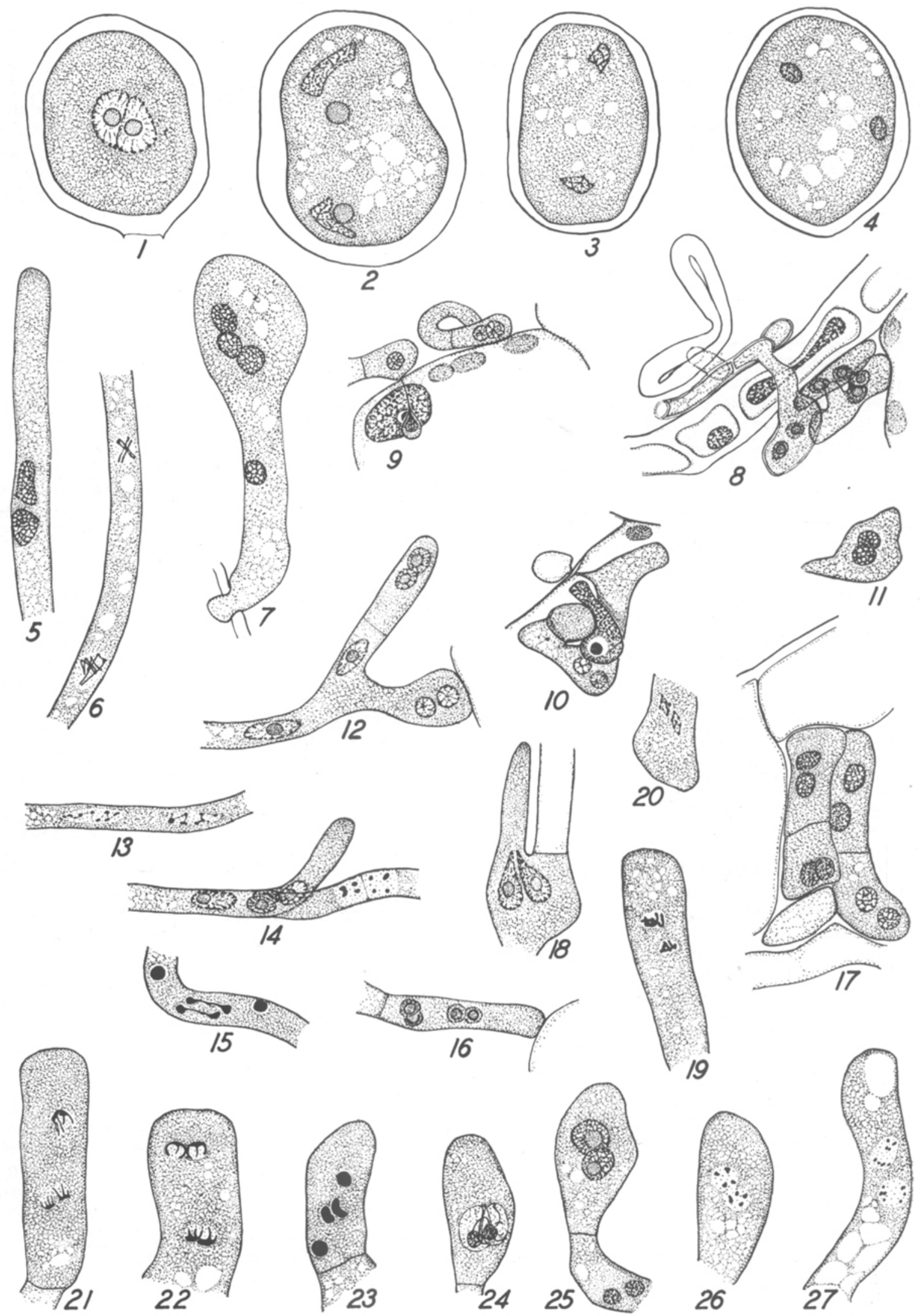


reacts to the Feulgen stain. At the same time it is not to be inferred that nothing but nucleoprotein is involved in the movement; but in such minute nuclei it is in general only the chromatin that can be distinguished from the karyolymph.

Heidenhain's haematoxylin, usually with orange $G$ as a counterstain, proved useful in the teliospore and basidium, particularly where it was desired to show spindle structure, and was used in other stages as a check on newer methods as well as to provide a comparison with the figures of earlier investigators. Its failure to render chromatin distinguishable from certain other materials, and the difficulty found in getting proper differentiation at certain stages owing to the accumulation of deeply stained ergastic material, are against its exclusive use: it should be used mainly when other methods fail.

Another point that should be more generally remembered is that the apparent size of minute structures stained by this method may be far greater than the true size. This is particularly true when chromic fixing fluids have been used. It is possible by this method to make the delicate spindle fibers distinctly visible, although in reality they are probably below the limit of vision. The method is similar to the mordanting and precipitation techniques used in demonstrating bacterial flagella. Other structures are similarly affected, and a stain heary enough to demonstrate the spindle often causes the chromosomes to appear as a single clump rather than as individuals. No other haematoxylin technique having been used, the method will be referred to simply as haematoxylin staining.

Other methods occasionally used have been the following: Safranin counterstained with fast green in clove oil; various modifications of Flemming's triple stain; aqueous methylene blue counterstained with erythrosin in clove oil; and Gram crystal violet counterstained with orange G. The Gram formula used was the rapid method of Dr. Guilford B. Reed, as given by Racicot, Savile, and Conners (1938). Its main use was in delimiting the inner nuclear sphere in certain stages.

The optimum thickness for paraffin sections in such a study as this was found to be $7 \mu$. Sections much thinner show few complete figures, and in sections appreciably thicker there is too much interference with the resolution of fine details, particularly if the more opaque dyes have been used.

The germination of aeciospores and urediniospores was studied mainly by germinating the spores upon thin agar films on slides. After appropriate intervals the preparations were fixed and were then handled like paraffin sections. Teliospore germination was studied in part by the use of sections and in part by scraping the germinating spores, or the basidia only in the case of Melampsora, into a drop of water upon a slide. After teasing the spores apart, a drop of fixing fluid was applied and allowed to dry, and the slide was then handled in the normal way. 'This apparently crude treatment sometimes yields remarkable results; even if half the basidia are lost, ample material remains if the germination was good.

Fig. 1-27. Unless otherwise stated, figures are reproduced at 1,990 diameters magnification. Abbreviations used are explained under "Materials and Methods."-Fig. 1. Nearly mature urediniospore of U. Fabae. Buffer. F. A. A.Fig. 9. Discharge of endospheres from nuclei of $U$. Fabae urediniospore. Feulgen. A. A.-Fig. 3. Later stage than figure 2 . Nuclei diminishing in size. Feulgen. A. A.-Fig. 4. Later stage than figure 3. Typical unexpanded nuclei. Feulgen. A. A.-Fig. 5. Unexpanded nuclei in germ-tube of $U$. Fabae urediniospore. Feulgen. F. A. A.-Fig. 6. Division of nuclei in germ-tube of $U$. Fabae urediniospore. Feulgen. F. A. A.-Fig. 7. Four unexpanded nuclei in germ-tube of U. Fabae urediniospore. Feulgen. F. A. A.-Fig. 8. Infection hypha of $U$. Fabae urediniospore. Collapsed spore seen on leaf surface. Several lobes formed on leaf surface before tube entered stoma. Three pairs of nuclei seen in the lobes in substomatal cavity, all partly expanded. Buffer. F. A. A. $\times 1480$.-Fig. 9. Dikaryon $U$. Fabae hyphae forming haustoria in parenchyma cell. In each appressorium the partly expanded nuclei have reverted to the unexpanded form. In that at left cell wall has been penetrated, and one nucleus is passing into the young haustorium. Buffer. F. A. A. $\times 1480$. - Fig. 10. Mature haustorium of $U$. Fabae coiling round and distorting nucleus of host cell. Haustorial nuclei still in unexpanded form. Buffer. F. A. A. $\times 1480 .-$ Fig. 11. Mature haustorium of $P$. Hiercicii. Nuclei unexpanded. Feulgen. A. A.-Fig. 12. Branched hypha of $U$. Fabae showing typical partly expanded nuclei above and unexpanded nuclei in lobe below where appressorium is forming prior to haustorium formation. Buffer. F. A. A.-Fig. 13. Anaphase in $U$. Fabae dikaryon mycelium. Feulgen. A. A.-Fig. 14. At right, late prophase in $U$. Fabae dikaryon hypha. At left, four partly expanded nuclei. Two in center, partly superimposed, are sliding past each other to restore the pairing of opposite strains; finally one pair would have moved out into new hyphal branch above. Buffer. F. A. A.Fig. 15. Two nuclei sliding past each other in dikaryon hypha of $P$. IIieracii following simultaneous division. Nuclei still almost unexpanded. Haematoxylin. F. A. D.-Fig. 16. Stage shortly after division in hypha of $U$. Fabae. Crossing of nuclei has probably already occurred; otherwise nuclei would be farther apart. Buffer. F. A. A.-Fig. 17. Buffer cells at edge of $U$. Fabae uredinium. Nuclei slightly expanded, but endosphere does not show with this stain. Feulgen. A. A.-Fig. 18. Basal cell of $U$. Fabae forming lobe before dividing to cut off spore mother-cell. Pedicel of mature spore still attached above. Buffer. F. A. A.-Fig. 19. Prophase of division in urediniospore mother-cell of U. Fabae. Feulgen. A. A.-Fig. 20. Anaphase of division in basal cell of U. Fabae uredinium. Feulgen. A. A.-Fig. 21. Telophase in $U$. Fabae urediniospore mother-cell. Nuclei farther apart than length of spindle. Feulgen. A. A.Fig. 22. Slightly later stage than figure 21 ; cutting out of endospheres from cytoplasm is in progress. Feulgen. A. A.Fig. 23. Stage just after division in $P$. Antirrhini spore mother-cell. Two nuclei evidently distorted while in motion to restore pairing, spindles not having been side by side. Haematoxylin. Chr. Ac.-Fig. 24. Young $U$. Fabae urediniospore. Chromatin moving out into ectosphere. Feulgen. A. A.-Fig. 25. As figure 94 but spore nuclei almost fully expanded. Pedicel nuclei unexpanded. Feulgen. A. A.-Fig. 26. Prophase of division in $U$. Fabae urediniospore pedicel. Buffer. F. A. A.-Fig. 27. Anaphase of division in $U$. Fabue urediniospore pedicel. Buffer. F. A. $\Lambda$. 
All examination of cytological detail was made with a Zeiss $\times 90$ apochromatic objective of 1.3 $\mathrm{N}$. A. and compensating eyepieces and with the condenser at about N. A.=1.2. The majority of the drawings were made with the $\times 15$ eyepiece and with the camera lucida adjusted to give a magnification of 2600 diameters on the drawing board; these are reproduced at a magnification of 1920 diameters. The few drawings reproduced at other magnifications have the scale indicated in the descriptions of the figures.

In the preparation of the figures it has sometimes been necessary to use slightly conventional methods, and these should be understood before the illustrations are studied. In the first place the limitations of monochrome rendering of details distinguished in the slide largely by color differences are quite serious. To make nuclear structures stand out from the surrounding cytoplasm, they have often been drawn somewhat more boldly than they appeared in the slide; but important dimensions, such as the diameters of the prophase chromosomes, have been reproduced as accurately as possible. In the second place, certain apparently amorphous structures, which cannot be reproduced naturally in a line drawing, have been indicated by a geometrical type of stippling to distinguish them from the reticulately stippled cytoplasm. Examples of this may be seen in figures 30, 31 and 34, and the method has also been used in a number of other drawings. Wall sculpturings have been left out in all drawings of spores since they are sometimes hard to distinguish without special methods, and they have no bearing on the present problem. For the sake of uniformity and to avoid further explanations, drawings have been oriented as though the host leaf were horizontal, and it has been assumed that all aecia opened on the lower surface and all other sori on the upper.

RESULTs.-The rust nucleus is commonly described and illustrated as having a relatively large nucleolus inside a reticulum that is very variable in both size and stainability. Sometimes the whole outer zone is represented as perfectly hyaline. At other times the entire nucleus is indicated as much smaller, being about the size of the so-called nucleolus, and it then contains either no visible nucleolus or only a very small granule the identity of which is hard to determine.

This variability puzzled the writer until a number of buffer-stained preparations were obtained in which a deeply-stained granule was visible in virtually every one of these inner spheres, or so-called nucleoli, of the larger, expanded type of nucleus (fig. 105). This granule could often be seen to be surrounded by an optically empty zone similar to the "heller Hof" commonly seen about the nucleolus in fixed nuclei of the higher plants. This at once suggested that the small granule, rather than the sphere in which it lay, was the nucleolus.

Attempts were made to secure adequate differentiation with haematoxylin to see low this inner sphere of the nucleus behaved during mitosis and the subsequent nuclear reconstitution. Although by this means it was often possible to distinguish the granule within the inner sphere (fig. 103), it was seldom possible to discern the details of division owing to the presence, in dividing cells, of some substance with a great affinity for the haematoxylin. If destaining was carried far enough to clear all the cytoplasm, the nuclei were also almost completely destained. This was particularly true of the aecia, but it applied also to all other stages except the basidium, in which the nuclei are not of the expanded type.

It was not until the Feulgen method was used in an attempt to determine the precise distribution of the chromatin in the different types of nuclei that their real behavior began to be understood. Most of the features of the nuclear cycle have now been worked out, and in order to make them clear it is proposed to trace the entire life-cycle of the typical heterothallic, long-cycled rust, starting with the urediniospore.

The morphology of the several fruiting structures has been described in detail for a number of genera by Moss (1926, 1929), Kursanov (1922), and Fromme (1914), among others, and will be taken up in the present paper only as it affects the problem at hand.

The uredinium.-The mature urediniospore has what will be termed the fully expanded type of nuclei (fig. 1) - that is to say, all the chromatin lies in the outer sphere, while the inner sphere is usually homogeneous in appearance and is a clear glassy green when the Feulgen stain is employed. It will soon be seen that these inner and outer spheres of the nucleus cannot be homologized with any parts of the nucleus of the higher plants and that they require distinctive names. It is proposed, therefore, to call them, respectively, the endosphere and ectosphere. These terms, while sufficiently descriptive to be useful, have the advantage of not implying any function that might later prove to be lacking.

Germination of the urediniospore is accompanied or preceded by a reversion of the nuclei to the unexpanded state - that is to say, they decrease in size and lack the endosphere, presenting instead the appearance of a small but typical nucleus. The change in form has been followed for Uromyces Fabae. The endosphere moves to one side until it lies against the ectosphere membrane. This membrane then breaks down locally and reforms behind the endosphere, which is accordingly left in a cupulate depression outside the nucleus. From here it drifts off into the cytoplasm (fig. 2) and eventually disintegrates. The greatly distorted nuclei now contract (fig. 3) and eventually round up into the typical unexpanded form (fig. 4). A minor disadvantage of the Feulgen method as here employed is that it is not possible to distinguish the true nucleolus of the unexpanded nucleus, everything but the chromatin being uniformly stained by the fast green. A recent paper by Semmens and Bhaduri (1939) deseribes a modification whereby the counterstain is removed from everything but the nucleolus; though satisfactory for chro- 
mosome studies in the higher plants, such a method would not meet the requirements of a problem of this kind. So far there has been no opportunity to perfect a differential stain for this purpose.

As germination proceeds, the nuclei move out into the germ-tube, either retaining the unexpanded form or becoming slightly expanded, with some of the chromatin outside what is then to be regarded as a new endosphere; but in either case the appearance with the Feulgen stain is unaltered, except that they may become somewhat distorted (fig. 5). If the host is not immediately penetrated the nuclei undergo simultaneous division in the germ-tube. The prophase of such a division is seen in figure 6 . It will be noticed that the dividing nuclei are far apart, and this seems to be generally true. It is improbable that the nuclei ever divide side by side in the tube. Where two nuclei having a dumbbell shape are seen abreast in a narrow hypha or germ-tube, it is probable that they represent two daughter nuclei slipping past one another to restore the pairing of compatible strains after division; this device takes the place of the clamp-connection. After the division, unexpanded nuclei are again formed, as shown in figure 7 ; here, incidentally, a secondary spore is in process of formation, as often occurs when germination takes place under unfavorable conditions.

Figure 8 shows the invasion of a pea leaf by the germ-tube of a urediniospore of Uromyces Fabae. The empty, collapsed spore can be seen on the leaf surface. It will be seen that several lobes were thrown out by the germ-tube before one reached and entered the stoma. It is interesting to note that these lobes, as well as the first one formed in the substomatal cavity, all have distinctly thickened walls that stain like the spore wall, being green because of the combined effect of the methylene blue and the yellow wall pigment. This indicates that the infection process took a considerable time and that even in the substomatal cavity conditions were not entirely favorable.

Three pairs of nuclei are present in the hypha, all in the partly expanded state typical of nuclei in the vegetative mycelium. The endosphere is plainly seen with the buffer stain, but when the Feulgen stain is employed the even distribution of chromatin throughout the nucleus makes it indistinct. The exact condition of the hyphal nuclei varies considerably: there may be a fairly large ectosphere, containing most of the chromatin; or all the chromatin may be in the endosphere, and the ectosphere visible only as a small hyaline zone. Rarely they are completely unexpanded, but, in general, it may be said that they are partly expanded unless performing some special function.

In order to establish itself, the mycelium must send haustoria into the host cells. The first certain indication that a haustorium is to be formed by a hypha in contact with a host cell is the reversion of the nuclei to the unexpanded form (fig. 9, 12). This type of reversion is brought about by the retreat of such chromatin as is in the ectosphere into the endo- sphere. The ectosphere meanwhile contracts to meet the membrane of the slightly enlarging endosphere. The altered appearance is very striking with the buffer stain, but, of course, is not apparent in Feulgen preparations. An extremely slender penetration thread is formed, and, at its end, a lobe into which the nuclei pass. At the left of figure 9 the first of the two nuclei has passed almost completely into the lobe. The haustorium nuclei typically preserve their unexpanded form, though a suggestion of a small outer sphere is sometimes seen, as in figure 11 .

A mature haustorium of Uromyces Fabae, with unexpanded nuclei, is shown in figure 10, closely investing and distorting the host nucleus. That the haustoria of this species are attracted in some way toward the host nuclei seems to be quite certain. They may penetrate the cell at any point, but once they have entered it they very soon become directed toward the nucleus. One occasionally sees two or three widely separated haustoria converging upon a centrally located nucleus. The most logical explanation for this seems to be that certain elaborated food materials must be obtained from the host nucleus, from which they diffuse, rather than merely from the cytoplasm.

Clear and easily interpreted division figures in the mycelium are difficult to find. Those that have been found indicate that these divisions are similar to those to be described in more detail in connection with the basidium. At the right of figure 14, a pair of nuclei is seen in late prophase with the chromosome contraction completed. Of the four remaining nuclei the two in the center are partly superimposed and are sliding past each other to restore the pairing of compatible strains. The extra space provided by the new hyphal branch above has allowed this to take place without the usual amount of distortion. Eventually two of these nuclei would have moved out into this new branch. When the nuclei are still in the unexpanded state they seem to be very fluid and become greatly distorted in the process of rearrangement. This is shown in figure 15 , which is the type of figure commonly regarded as a conjugate telophase. Such an interpretation looks upon the two stationary nuclei as persistent, discharged "nucleoli." The partly expanded nucleus does not discharge its endosphere, however; the endosphere merely increases slightly in size, and the division starts within it, and later its membrane breaks down.

When four nuclei are seen in a cell just after division, it does not seem possible to tell from the degree of their expansion whether the rearrangement has taken place. If, however, the nuclei are very closely associated in pairs, as in figure 16 , it is probably safe to assume that it has already occurred, for sister nuclei are mutually repulsive and so would be separated by at least the length of the spindle.

Figure 13 shows a pair of hyphal nuclei in anaphase. The divisions in the two nuclei usually proceed at exactly the same pace, as in this example.

When a new uredinium is formed, a number of thin-walled but turgid buffer cells are produced first 

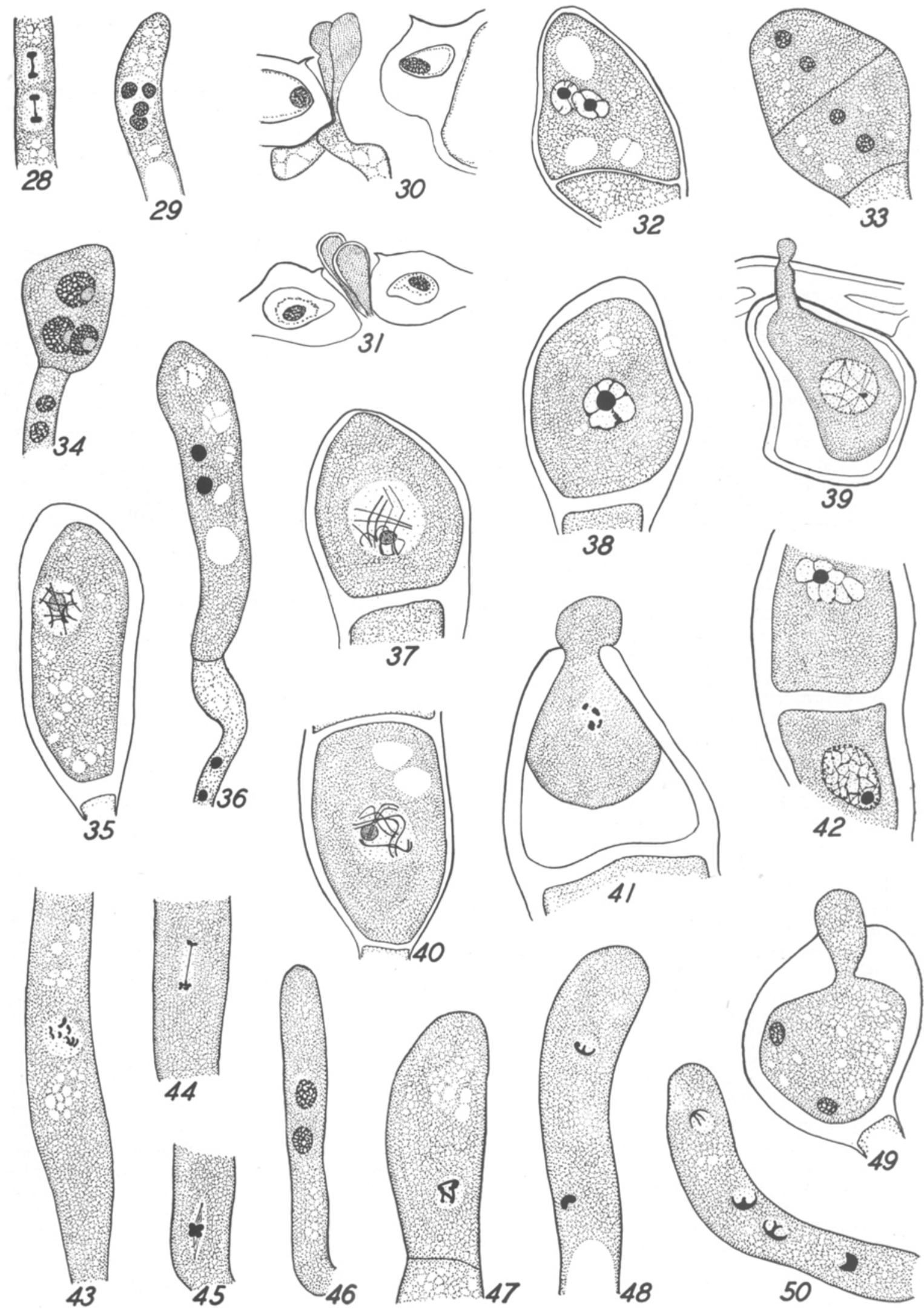
at its center and later at its edges for the purpose of lifting the epidermis and allowing unhindered derelopment of the spores. The nuclei of these cells stand out in sharp contrast to those of the spores (fig. 17), being only very slightly expanded.

Disregarding the general morphology of the uredinium, we turn next to the divisions leading to the production of the spores. These are two in number: that by which the basal cell cuts off the spore mothercell and that by which the mother-cell is separated into spore and pedicel. These divisions have never been followed accurately, only the telophase usually being depicted. They are considerably more difficult to distinguish than those in the aecium, which will later be described in detail, but it is thought that they are essentially similar. The nuclei of both the basal cell and the spore mother-cell become completely expanded and so must almost certainly divide in the manner typical for this form, with the prophase chromosomes lying outside the endosphere in the ectosphere cavity. The spore mother-cells are successively budded off from the basal cell, as shown in figure 18, a new one being formed laterally before the pedicel of the previous spore has disappeared.

Figure 19 shows the nuclei in prophase in a spore mother-cell; the chromosomes have contracted slightly, and the ectosphere membranes and the endospheres have disappeared. A basal cell in anaphase is shown in figure 20 ; the spindles appear slightly shorter than they actually are, because they are not in the exact plane of the slide. The telophase and nuclear reconstruction can be clearly followed and, together with similar stages at other parts of the life-cycle, supply further evidence that the endosphere is very different from the nucleolus as it is properly understood. The separating chromosome groups become arranged more or less in a square and take on the appearance of a flat plate from which delicate strands are often seen to trail (fig. 21). They move considerably farther apart than the length of the spindle, and then (fig. 22) curved proc- esses of chromatin are thrown out from the chromatin plate to cut out a sphere from the cytoplasm. There are apparently about four of these processes; this suggests that they may actually be the chromosomes returning to the metabolic state. They soon anastomose to form a reticulate hollow sphere.

In these divisions there is usually plenty of room for the spindles to be formed side by side, and this position is commonly attained before telophase starts. Occasionally the orientation apparently fails to take place, and the nuclei are partly reorganized before pairing at the top and bottom of the cell. Figure 23 probably represents such a rearrangement; though, this being a haematoxylin preparation, it is not possible to be certain that the spherical bodies are not endospheres and the two bodies in the center imperfectly differentiated prophase figures. One argument against such an interpretation is that daring the actual divisions it is usually impossible to get the cytoplasm as clear as in this figure and still keep the nuclei black.

After the second division, the two pairs of nuclei behave differently. Those in the pedicel remain unexpanded or virtually so, part of the chromatin passing into the central part of the nucleus and giving it an evenly reticlulate appearance (fig. 25 ). The chromatin of the spore nuclei may all remain for a short time at the periphery of the sphere cut out from the cytoplasm, or some of it may pass into its center but before long a large ectosphere is delimited from the cytoplasm by the formation of vacuoles that gradually coalesce (fig. 24), the chromatin passes out toward the periphery of this, and the endosphere is soon left without any. The chromatin may nearly all pass to the outer membrane of the ectosphere or it may remain in a regular reticulum (fig. 25).

An interesting phenomenon rather frequently seen in Uromyces Fabae is the division of the pedicel nuclei. Four reformed nuclei have been found only once (fig. 29), and the telophases (fig. 28) are not common, but the earlier stages have been found

Fig. 28-50.-Fig. 28. Telophase of division in $U$. Fabae urediniospore pedicel. Buffer. F. A. A.-Fig. 29. Four reconstituted nuclei in $U$. Fabae urediniospore pedicel. Buffer. F. A. A.-Fig. 30. Hyphal tips emerging from stoma close to $U$. Fabae uredinium, end pinched off in closing of stoma.-Fig. 31. Hyphae similar to those in figure 30, in lifted epidermis over $U$. Fabae uredinium.-Fig. 32. Partly expanded dikaryon nuclei in young teliospore of $P$. $M a l-$ zacearum. Haematoxylin. Chr. Ac.--Fig. 33. Unexpanded nuclei in young teliospore of P. Hieracii. Haematoxylin. F. A. D.-Fig. 34. Young teliospore of T. fusca, showing early expansion of nuclei. Those of upper cell have already fused although septum between cells has not yet formed. Feulgen. F. A. A.-Fig. 35. Fusion nucleus in $U$. Fabae teliospore, showing leptonema threads. Feulgen. A. A.-Fig. 36. P. Malvacearum teliospore before final division. Nuclei unexpanded. Haematoxylin. F. A. D.-Fig. 37. Zygonema stage in P. Malvacearum teliospore. Haematoxylin. Chr. Ac.--Fig. 38. Partly expanded fusion nucleus in P. Malvacearum teliospore. Haematoxylin. Chr. Ac.-Fig. 39. Germinating $M$. Bigelozii teliospore in Salix leaf. Nucleus approaching leptonema. Haematoxylin. F. A. A.-Fig. 40 . Zygonema in P. Malvacearum teliospore. Four pairs of threads seen. Haematoxylin Chr. Ac.-Fig. 41. Diakinesis in germinating $P$. Malvacearum teliospore. Chromosomes too closely paired for individuals to be discerned. Haematoxylin. F. A. A.-Fig. 42. P. Malvacearum teliospore, showing lower nucleus completely expanded while ectosphere of upper nucleus is still forming and little chromatin seems to have left endosphere. Haematoxylin. Chr. Ac.Fig. 43. Diakinesis in P. Malvacearum basidium. Haematoxylin. Chr. Ac.--Fig. 44. Late anaphase of first division in P. Malvacearum basidium. Haematoxylin. Chr. Ac.-Fig. 45, Metaphase in first division in P. Malvacearum basidium. Haematoxylin. Chr. Ac.-Fig. 46. Unexpanded interphase nuclei in $U$. Lespedezae-procumbentis basidium. Feulgen. D. G.-Fig. 47. Prophase of second division in P. Malvacearum basidium. Haematoxylin. Chr. Ac.-Fig. 48. Late telophase of first division in $P$. Malvacearum basidium. Haematoxylin. F. A. D.-Fig. 49. Unexpanded interphase nuclei within germinating teliospore of $U$. Lespedezae-procumbentis. Feulgen. F. A. A.-Fig. 50. Late telophase of second division in $M$. Bigelowii basidium. Haematoxylin. F. A. A. 
rather frequently in some collections. A late prophase is shown in figure 26, and an anaphase in figure 27. These figures stain well with the buffer method and are clearer than those usually obtained in the hyphae. This is partly explained by the small amount of ergastic material found in these cells and partly, perhaps, by the scanty cytoplasm. The reason for this seemingly functionless division is not certain. The only apparent clue to its origin that the writer has been able to find is in Fromme's (1912) investigation of Melampsora Lini. He showed that the urediniospore pedicels of this rust are commonly two- or three-celled. The divisions in $U$. Fabae may be a relic of this condition.

Associated with the uredinial stage in some of the material of $U$. Fabae were rather numerous hyphal tips emerging from the stomata. These seem to have been short-lived, since nearly all those seen had been pinched off by the closing stomata, as in figure 30 . The contents are amorphous in appearance rather than granular or reticulate, and so were presumably not living at the time of fixation. These hyphae are very similar in appearance to those seen by Andrus (1931) associated with the pycnia of Uromyces appendiculatus, and by Rice (1933) associated with the pycnia of Puccinia Sorghi. Both these writers considered them to be trichogyne tips. Ashworth (1935a) showed that such hyphae occur close to the uredinia or telia of several rusts, including some that are apparently homothallic. These findings clearly indicate that such hyphae, though they may possibly serve as receptive hyphae, are not to be regarded as specific female structures. Actually they seem to be formed wherever the mycelium is massed under the epidermis and their emergence is probably largely a matter of chance, though it may be influenced by the external environment. A careful examination of the ruptured epidermis over the uredinia revealed many such tips broken off and lodged in the stomata (fig. 31 ).

Allen (1935) described what she considered to be conidia cut off from the apices of stomatal hyphae of Puccinia Malvacearum and suggested that they might take the place of the pycniospores in this rust. As Ashworth (1931) showed fairly convincingly, however, that this rust is homothallic, and so not in need of such spores, it seems probable that what Allen saw were hyphal tips cut off in the manner here described.

The telium and basidium.-The development of the telium in Puccinia and Uromyces, with which we are chiefly concerned, is essentially the same as that of the uredinium. In Puccinia there is one extra division in the formation of the two-celled spores, but this division presents nothing new. The nuclei eventually become expanded before this final division, but they may remain unexpanded for some time (fig. $36)$, while the cell is increasing in size. The next stage of importance comes immediately after this final division in the formation of the teliospore, when the nuclei become expanded and fuse. There seems to be great variation in the rate of these processes, in relation both to each other and to the development of the spore wall. Figures $\mathbf{3 3}$ and $\mathbf{3 4}$ form a remarkable contrast. Figure $\mathbf{3 3}$ shows a young spore of Puccinia Hieracii; here the formation of the ectospheres has not yet started, although the septum between the cells is complete. The teliospore of Transchelia fusca is also two-celled. In the example shown in figure 34 not only have all the nuclei become fully expanded, but those of the upper cell have already fused, although no sign of a septum could be seen. Figures 34 and 12 provide a further contrast. The nuclei of the lower cell in figure 3.4 have become completely expanded before fusion. In figure 42 , representing a teliospore of Puccinia Malvacearum, the two nuclei of the upper cell have fused, although expansion is not nearly complete.

The process of nuclear expansion is very clearly seen in the teliospore. As already mentioned it is initiated by the formation of a number of vacuoles around the unexpanded nucleus. The irregular shape seen in the upper cell of figure 42 is rather exceptional, but slightly lobed outer zones, such as are shown in figures $\mathbf{3 2}$ and 38 , are commonly seen. The vacuoles gradually coalesce and the newly-formed ectosphere takes on a smooth periphery. At the same time, the chromatin gradually leaves the endosphere, passing along the protoplasmic strands in which it is supported. Finally the chromatin becomes disposed in a typical open reticulum, as in the lower cell in figure 12 .

The delicacy of the chromatin strands makes difficult the exact identification of the early stages of the first meiotic division in the fusion nucleus, but some have been clearly recognized. During the expansion the endosphere decreases somewhat in size. It may continue to dwindle and to be almost completely disintegrated at the start of prophase (fig. $39)$; but as a rule it persists almost unchanged until the pairing of the elongated chromosomes is complete. The endosphere then disintegrates rather rapidly, as is shown both by its decreased size and by its decreased stainability.

The first indication of the start of prophase is the change of the chromatin from a reticulum to a number of strands that at first seem to have no wellordered arrangement and whose individuality is not clear (fig. 39). A slightly later stage is shown, for Uromyces Fabae, in figure 35 . In this spore the threads are more distinct, but they seem to be distributed at random throughout the ectosphere. Their exact number cannot be ascertained, since it is of ten impossible to distinguish two adjacent threads from a single sharply bent one. The next recognizable stage is the zygonema, of which several good examples have been found in Puccinia Malvacearum. In figure 37 the number of chromosomes is in doubt, because the pairing is not complete and the threads are greatly contorted toward the basal side of the nucleus. In figure 10, however, there seems to be little doubt that the number of pairs is four, since all the ends lie free from one another. The exact length of the threads cannot be determined, since their con- 
volutions are in both the vertical and horizontal planes, but they are surprisingly long. One pair seems to be about $8 \mu$ in length, a second about $6 \mu$, and the others from 4 to $5 \mu$.

The chromosomes apparently contract very abruptly after pairing, for it lias not been possible to find the next prophase stages with the exception of an occasional rather indistinct diakinesis. Actually the chance of discerning any doubleness of the threads in the missing stages with such unfavorable material is small. Figure 41 shows the nucleus about to pass into the basidium in what is evidently diakinesis; there are two small and two relatively large clumps of chromatin.

As far as could be judged from the material examined, the stage at which the nucleus leaves the teliospore varies somewhat with the species. In $M e-$ lampsora Bigelowii it generally seems to migrate before the pairing of the chromosomes (fig. 39). In Puccinia Malvacearum it generally passes into the basidium between zygonema and diakinesis, whereas in Uromyces Lespendezae-procumbentis division may become far advanced in the spore and may even be completed within it (fig. 49). It is not certain that this is an inherent tendency of the species, since it may conceivably be influenced by the physiological state of the material at the time of germination.

The stage shown in figure 43 is not very easily identified, but since the individual chromosomes are distinct it is presumably somewhat later than that seen in figure 11 , and immediately precedes the formation of the spindle. The metaphase itself is clearly seen in material heavily stained with haematoxylin (fig. 45), as is the succeeding anaphase, but the heary stain required to bring out the spindle usually makes a chromosome count impossible by causing the chromosomes to appear clumped.

In late anaphase it often looks as though there were only two chromosomes going to each pole, and this effect in particular seems to account for the chromosome count of two given by Sappin-Trouffy for all species examined by lim. Careful focussing reveals that each body is actually two superimposed cliromosomes. This is shown in the late anaphase seen in figure 44. At the upper end of the spindle there seems to be merely a two-lobed chromatin mass; but the lower end is viewed somewhat oblique$1 y$, and it is seen that there are four bodies arranged approximately in a square, though even here only two of the group could be brought into focus at the same time.

Occasionally end views of anaphases have been seen in sections of germinating Puccinia Malvacearum sori, and these confirm the arrangement of the chromosome groups in a square. Such views do not lend themselves to illustration, but it is possible to draw the two groups separately, which shows that there are two very small chromosomes and two slightly larger ones in each group. The larger ones, allowing for the foreshortening effect that obtains when they do not lie quite parallel to the slide, have been calculated to be about $0.5-0.7 \mu$ long, and the shorter ones seem to be about $0.25 \mu$ long. The diameter of each seems to be about $0.20-0.25 \mu$.

It is at first difficult to see how such long threads as those shown in figure 40 can contract in anaphase to the dimensions indicated. The explanation probably is that the apparent diameter of the prophase threads is much greater than the true diameter. Two factors may contribute to such an effect. In the first place, the diameter is increased by the adsorption or precipitation of dye and, perhaps, other material upon the chromosomes. Though both the long and the contracted chromosomes will be affected, the proportionate increase will be far greater for the thin thread. In the second place, the diameter of the stained prophase threads, though just above the limit of actual vision, is considerably below the limit of true resolution. With green light the resolving power of an objective with a numerical aperture of 1.3 is about $0.2 \mu$ with a full condenser cone. Objects appreciably narrower than this are usually invisible if lightly colored, but if deeply stained they will be discernible and will appear considerably broader than they really are. If the prophase threads contract without change in volume, their calculated diameter when at their maximum length is about 0.04 $\mu$. The contraction probably is accompanied by some loss in volume, but even so the true minimum diameter must be considerably less than $0.1 \mu$.

No well-defined centrosomes have been seen in any of the forms studied, though small dots are sometimes visible at the ends of the spindle in haematoxylin preparations. These may be centrosomes, but it seems possible that they are simply optical effects. The spindle fibers, even when heavily stained, are so far below the limit of resolution that they appear gray; but where they meet at the end of the spindle they may build up to a size approaching the limit of resolution and so appear black.

Allen (1933b), in her study of the germination of the teliospores of Puccinia Malvacearum, suggested that the liaploid number was five. The chromosomes are so small that it is often impossible to be certain whether one is looking at one relatively large, or two adjacent, very small ones. The writer's observations, gleaned from both prophase and anaphase figures, indicate a haploid number of four for this species and for Uromyces Fabae, U. Hyperici, Puccinia Sorghi, and Melampsora Bigelowii. Observations on other species do not warrant an estimate.

The groups of chromosomes usually move far apart during telophase (fig. 48) and cut out new spheres from the cytoplasm in the manner already described. The nuclei become reticulate but remain unexpanded (fig. 46). To judge from the small number of metabolic nuclei seen at this stage, the interphase must be short.

The second division is typical of that of unexpanded nuclei in other parts of the life-cycle. In the prophase seen in figure 47 , chromosome contraction had probably already commenced, since the threads are rather thick; but in this division, and in all the mitotic divisions, it seems that the prophase chromo- 


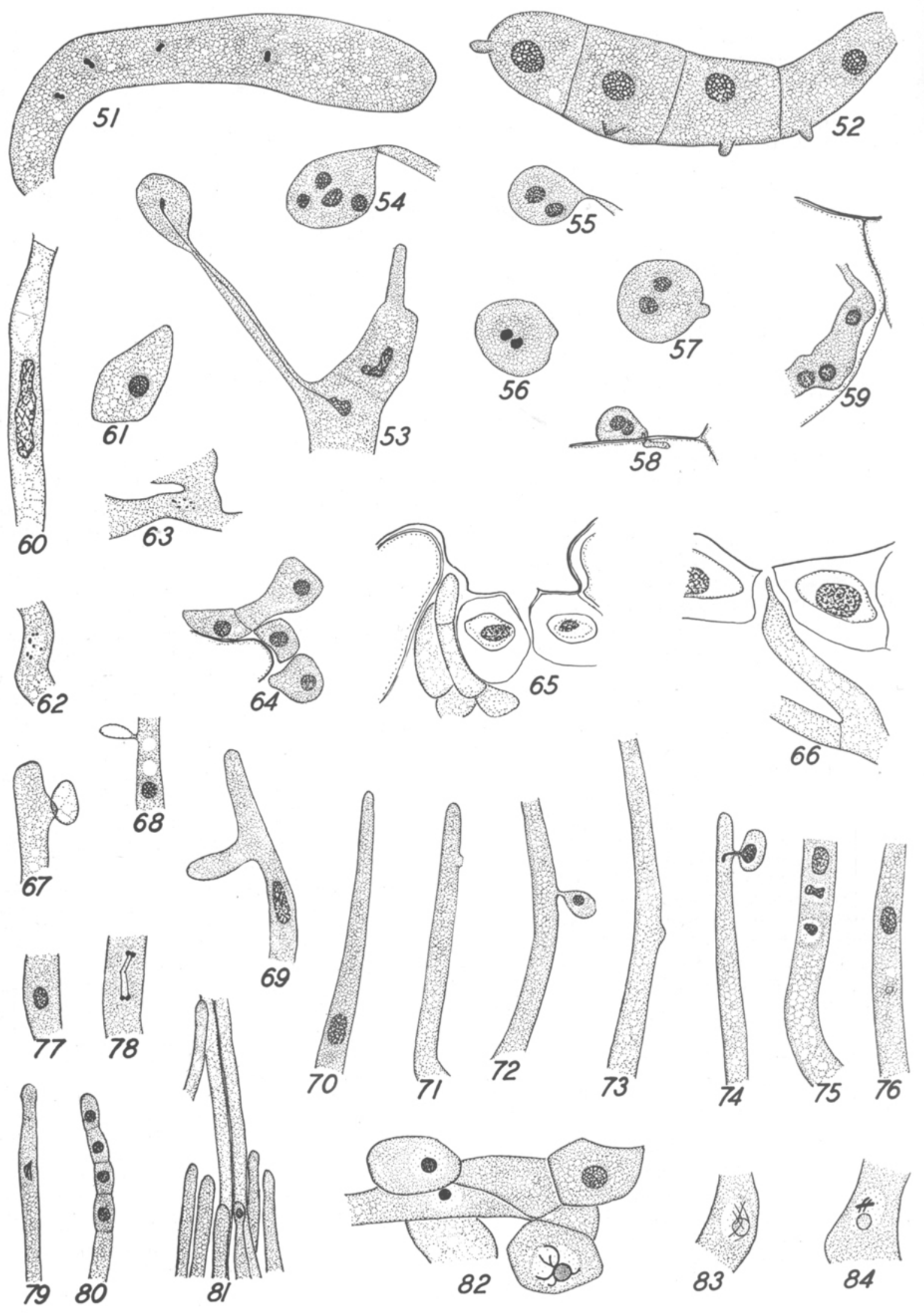


somes attain only about half the length of those seen in the fusion nucleus.

The period at which the first septum is laid down in the basidium varies greatly, but it has never been seen to form until all traces of the spindle have disappeared. It may be formed at the time of the prophase of the second division (fig. 47 ), but it is commonly delayed until the telophase (fig. 51), or even nuclear reconstruction following this division (fig. 50 ). Nuclear reconstruction is similar to that following the first division, and the septa between the products of the second division form promptly, resulting in a four-celled basidium with unexpanded nuclei. For some reason these nuclei seldom stain strongly eren with haematoxylin or the Feulgen stain, and occasionally they are indistinguishable. Not only is the ergastic material, on which the buffer stain is dependent, almost entirely absent, but the chromatin seems to be in a more delicate reticulum than usual, and the threads may be below the limit of vision.

'The formation of the sterigmata starts as soon as the basidium becomes four-celled. Their length depends largely upon whether or not there is water upon the leaf surface. If the basidium is almost completely immersed, the lower sterigmata usually become very long, in order to raise the spores clear of the surface. The nucleus passes into the spore before the latter attains its full size, and becomes greatly constricted in passing through the apex of the sterigma. When the latter is longer than usual, this attenuation of the nucleus may be very remarkable (fig. 53).

Allen (1933b) has already shown for Puccinia Malvacearum that the basidiospore nucleus divides before the germination of the spore. The present study has confirmed this and has shown the same to be true of Uromyces Lespedezae-procumbentis and Melampsora Bigelowii. Figure 56 shows the telophase of the division in $M$. Bigelozvii, and figure 57 shows the two unexpanded nuclei. In $U$. Lespedezaeprocumbentis the division commonly occurs before the spore is discharged (fig. 55), or even before it reaches its full size. On one occasion a quadrinucleate spore was found in this species (fig. 54). Since the basidium was not intact, it was not possible to determine whether this represented an extra division or whether two nuclei from the basidium had passed into the spore.

The monolaryon thallus.-The basidiospore germinates by forming a very short germ-tube and an appressorium and then enters the host by sending a slender process directly into an epidermal cell (fig. 58 ). One or more nuclear divisions normally occur after penetration; the intracellular hypha accordingly contains several unexpanded nuclei (fig. 59). Then septation occurs, and at least one of the cells pierces the inner wall with a slender thread, and its nucleus passes into the intercellular space to initiate the normal intercellular mycelium. Only then do the nuclei become partly expanded.

The nuclei of the monokaryon mycelium are essentially similar to those of the dikaryon. They range from the greatly extended form illustrated in figure 60 , commonly found in old hyphal cells, to the unexpanded or scarcely expanded forms seen in the pseudoparenchyma cells bounding the aecial primordium (fig. 61) or the pycnium (fig. 64). Divisions are even harder to distinguish than in the di-

Fig. 51-84.-Fig. 51. Early telophase of second division in M. Bigelorai. Feulgen. F. A. A.-Fig. 59. Unexpanded nuclei after second division in $M$. Bigelowii basidium. Haematoxylin. F. A. A.-Fig. 53. Nucleus passing into U. Lespedezae-procumbentis basidiospore. Feulgen. F. A. A.-Fig. 54. Quadrinucleate U. Lespedezae-procumbentis basidicspore. Feulgen. F. A. A.-Fig. 55. Normal binucleate basidiospore of U. Lespedezae-procumbentis. Feulgen. F. A. A.-Fig. 56. Telophase of division in $M$. Bigelowii basidiospore. Feulgen. F. A. A.-Fig. 57. Normal unexpanded nuclei in $M$. Bigelowii basidiospore. Feulgen. F. A. A.-Fig. 58. P. Sorghi basidiospore penetrating epidermal cell of Oxalis leaf. Feulgen. F. A. A.-Fig. 59. Intracellular infection hypha of $P$. Sorghi; unexpanded nuclear form retained. Feulgen. F. A. A.-Fig. 60. Partly expanded nucleus in old hyphal cell of U. Lespedezae-procumbentis; endosphere not distinguishable with this stain. Feulgen. F. A. A.-Fig. 61. Unexpanded nucleus in pseudoparenchyma cell close to aecium of $U$. Fabae. Feulgen. F. A. A.-Fig. 62. Anaphase figure near base of partly diploidized aecium of $U$. Fabae. Buffer. F. A. A.-Fig. 63. Same as figure 62. Buffer. F. A. A.-Fig. 64. Unexpanded nuclei in pseudoparenchyma bordering pycnium of $U$. Lespedezae-procumbentis. Feulgen. F. A. A.-Fig. 65 . Hyphae of $P$. Sorghi pushing between epidermal cells of Oxalis leaf. Feulgen. D. G.-Fig. 66. U. Fabae stomatal hypha with tip pinched off by closing of stoma.-Fig. 67. Empty $U$. Fabre pycniospore attached to papillate ostiolar hypha. Safranin. F. A. A.-Fig. 68. Partly collapsed P. Sorghi pycniospore attached to hypha. Feulgen. F. A. A.Fig. 69. Branched blunt hypha emerging from P. Sorghi pycnium. Feulgen. D. G.-Fig. 70. Typical ostiolar paraphysis from $P$. Sorghi pycnium. Feulgen. F. A. A.-Fig. 71. Papillate ostiolar hypha of $P$. Sorghi; fixed four hours after mixing nectar.-Fig. 72. Pycniospore attached to $P$. Sorghi ostiolar hypha; fixed four hours after mixing nectar. Feulgen. D. G.-Fig. 73. Papillate ostiolar hypha of U. Lespedezae-procumbentis; fixed thirty hours after mixing nectar.-Fig. 74. $U$. Fabae pycniospore nucleus passing into slightly tapering hypha. Methylene-blue erythrosin. F. A. A.-Fig. 75. P. Sorghi ostiolar hypha with one relatively large hyphal nucleus and two small introduced nuclei; fixed four hours after mixing nectar. Feulgen. D. G.-Fig. 76. P. Sorghi ostiolar hypha with thin a rea on wall; fixed two hours after mixing nectar. Feulgen. F. A. A.-Fig. 77. Resting nucleus of $U$. Fabae pycniosporophore. Feulgen. F. A. A.-Fig. 78. Telophase of division in U. Fabae pycniosporophore. Feulgen. F. A. A.-Fig. 79. Prophase of division in $U$. Iyperici pycniosporophore Feulgen. F. A. A.-Fig. 80. Catenulate pyeniospores of $U$. Lespedezae-procumbentis, showing unexpanded nuclei. Feulgen. F. A. A.-Fig. 81. Hyphae growing up into ostiole from base of $U$. Lespedezec-procumbentis pyenium. $\times 1330 .-F i g .82$. Cells at base of $P$. Sorghi primordium prior to diploidization; at left, two unexpanded nuclei; at right above, partly expanded nucleus; below, nucleus with chromatin passing out to periphery of ectosphere. Feulgen. D. G.-Fig. 83. Prophase of division of expanded nucleus in $P$. Sorghi primordium. Feulgen. D. G.-Fig. 84. Slightly later stage than figure 83; same preparation. 
karyon, where one of the two nuclei may be so oriented that the stage can be seen. Two anaphases, from close to the base of a young aecium of Uromyces Fabae in which diploidization was just starting, are shown in figures 62 and 63 . These will be further discussed in connection with the diploidization process.

The monokaryon haustoria are formed in essentially the same way as those of the dikaryon mycelium and, except for being uninucleate, are essentially similar in appearance. A single binucleate haustorium was found in a monokaryon pustule of Uromyces Fabae, but this is clearly to be regarded as an abnormality. The nuclei normally retain their unexpanded form, but a hyaline zone is sometimes seen around them, which probably indicates the initiation of the ectosphere. In very old haustoria they often take on an irregular form and may increase in size.

The pycnium and the introduction of pycniospore nuclei.-The pycnial stage is, of course, particularly interesting because of its importance in connection with the process of diploidization. Considerable attention was therefore devoted to it in an effort to find out more about the mechanism by which pycniospore nuclei of the compatible strain are brought to the aecial primordium. While this was not completely successful, some additional information was obtained that may help to lessen the existing confusion. A great deal of material of Puccinia Sorghi and Uromyces Fabae was examined, and smaller amounts of material of $U$. Lespedezae-procumbentis and $U . H y p e r i c i$. The two latter, and $U . H y p e r i c i$ in particular, have smaller nuclei than the other species and so are less suitable.

Particular attention was devoted to the occurrence of emergent hyphae, whether of the stomatal, epidermal, or ostiolar type. The observations made add weight to the writer's opinion that the stomatal and epidermal hyphae are formed largely by chance. Stomatal hyphae were occasionally seen close to the pycnia, but always with their tips crushed by the stomatal movement (fig. 66). Hyphae pressing up between the epidermal cells were often seen (fig. 65 ), but never breaking througl the cuticle. The remnants of both types can often be seen in the crushed epidermis bordering the ostiole of the pycnium, which strengthens the belief that they are the result of a massing of mycelium beneath the epidermis and are not specialized organs.

Several times whole pustules of Puccinia Sorghi and Uromyces Fabae, in which diploidization had just started, were carefully examined, and were found to be without any emergent hyphae, other than those from the ostioles. Although these epidermal. and stomatal hyphae, if better developed, may serve as supplementary receptive hyphae, it seems clear that in these two species the ostiolar hyphae are considerably the more important.

Craigie (1933) and Buller (1938) distinguished two types of ostiolar hyphae: the stiff, tapering, marginal paraphyses, and thin-walled, flexuous hy- phae with blunt ends, varying greatly in length and abundance and emerging more nearly from the middle of the ostiole. Only the latter were considered to be receptive. Their origin has not been clearly demonstrated, but it is logical to believe that they arise from lower on the wall of the pyenium than do the marginal paraphyses.

Hunter (1936), in a morphological study of the pycnia of the Melampsoraceae, saw groups of such hyphae arising from the center of the pycnium in a number of species. She also pointed out that Colley (1918), to whom their function was naturally obscure, saw similar hyphae in Cronartium ribicola. In this family there are no paraphyses, and there is every reason to believe that Hunter's suggestion that these are receptive hyphae is correct. Moreover, free-hand sections revealed pycniospores clinging to them. No such large groups of hyphae seem to arise from the bases of the pycnia in the Pucciniaceae, but individual hyphae, or groups of two or three, may occasionally be found. Figure 81 shows parts of two old hyphae and the tip of a young one arising from the center of the base of a pycnium of Uromyces Lespedezae-procumbentis. The older hyphae could be followed to the ostiole in the adjacent section, but could not be traced to the end. If a hypha passes completely through the congested region within a single section it may be possible to trace its entire length, but as a rule only free-hand sections permit determination of the full extent of the apical part of a long emergent hypha. These, unfortunately, are virtually useless for following it through the ostiole. That the flexuous hyphae do not always arise from the base of the pycnium in the species studied is evident, however, for many pycnia, with hyphae that are definitely of the flexuous type, show no hyphae arising from lower than about halfway up the sides of the cavity. The lowest of such hyphae usually emerge approximately in the center of the ostiole.

Not all writers have been able to distinguish the two types of ostiolar hyphae, a fact that is partly explained by the rarity with which a complete hypha of any great length will occur intact in a paraffin section; but the problem is further complicated by the frequent lack of a sharp distinction between the two types. In all the species studied, the writer found that if all the hyphae in a central section were drawn, there was nearly always a complete gradation from the typical paraphysis (fig. 70) at the edge to the blunt and often branched hypha toward the center. It is not possible to divide them into the two clearly separate types shown by Buller (1938) in his sketch of the pycnia of Puccinia graminis.

The most satisfactory stain for this phase of a cytological study of the rusts is unquestionably Feulgen's. The pycniospores stain very poorly with the buffer stain and not much better with haematoxylin. The fact that the cytoplasm of the ostiolar hyphae does not stain well adds further to the difficulty. The apical parts are invariably light pink when the buffer stain is used. This reaction suggests that the cytoplasm contains some of the ergastic material 
that is normally found in the nuclei but is absent from those of the pycniospores. They are also often slightly tinged with pink when the Feulgen stain is used and never take the counterstain as strongly as does the vegetative mycelium. There is evidently some substance present that gives an aldehyde reaction; but whether it is really a nucleoprotein or merely some ergastic substance, perhaps formed as a result of the altered environment of the hyphae, is not clear.

The nuclei of the pycniospores are spherical and unexpanded (fig. 72, 80), those of the emergent hyphae elliptical and partly expanded (fig. 69, 70). The nuclei of the pyeniosporophores are sometimes expanded to some extent, but are very often compact and apparently unexpanded (fig. 77). This compactness is explained by the fact that they divide so frequently to produce new spores that they have little time to expand. Prophase figures with the chromosomes lying approximately parallel (fig. 79) can be found, but the metaphase and anaphase stages have not been clearly distinguished. Telophases stain very clearly and may be found in almost any section. For some reason the spindle, just before it disappears, is often sharply bent (fig. 78).

Hunter (1936) describes the pycniospores as being typically catenulate in the Melampsoraceae. A tendency toward this habit was occasionally observed in Uromyces Lespedezae-procumbentis (fig. 80 ), but generally, in the species studied, one spore is discharged before the next one starts to form.

Very few convincing examples of pycniospores attached to receptive hyphae were found. Spores were often seen in contact with the hyphae, but it was only occasionally that definite evidence of union could be found. Figure 67 shows an empty spore of Uromyces Fabae attached to a large papilla near the tip of a blunt hypha. Figure 74 shows another fusion in $U$. Fabae, in this case with a slightly tapering hypha. This preparation was not well-stained, but the nucleus appears to be starting to migrate into the hypha. The fusion papilla is in this case much smaller. Figure 68 shows an empty and partially collapsed spore of Puccinia Sorghi attached to a slightly tapering hypha. The small rounded nucleus is probably that of the spore, the hyphal nucleus being lower down and out of the section. Well-marked vacuoles, such as are seen in this figure, often accompany great activity in a cell, and these suggest that nuclear migration had only just occurred. Figure 72 shows another fused pycniospore of $P$. Sorghi, this time with the nucleus still in the spore.

Branched hyphae (fig. 69) are not uncommonly seen in $P$. Sorghi. They seem to be essentially similar to those shown by Buller (1938) in his figure 3, but nothing approaching the length indicated by him has been seen in either paraffin or free-hand sections of any of the species examined. The length of these hyphae may be dependent upon the environmental conditions. Pycniospores were on several occasions seen in contact with the tips of these short side branches but were never so oriented that it could be definitely decided whether they had actually fused to them or were merely in chance contact.

Two other evidences of the introduction of pycniospore nuclei through the ostiolar hyphae were found in material fixed a few hours after mixing the nectar. The first of these is the occurrence of small papillae on the more flexuous hyphae. These may appear rounded (fig. 73), or the top may be flattened and extremely delicate (fig. 71). What is evidently the same structure as this last may be seen in surface view. By focussing very carefully upon the upper or lower wall of a hypha, using not too strong a light, small circular bright areas may occasionally be seen. Figure 76 shows the typical size of such a spot: its actual appearance is beyond the scope of a line drawing. These thin areas and papillae evidently represent places at which pycniospores were attached at the time of fixation. The second additional evidence is the occasional presence of several nuclei in a hypha. They are likely to be somewhat distorted and abnormal in appearance, but react characteristically to the Feulgen stain. Two such nuclei are seen below the hyphal nucleus in figure 75. The abnormal shapes may be due to violent streaming associated with the passage of the introduced nuclei past the hyphal nucleus or may indicate the beginning of nuclear division. Since plurinucleate ostiolar hyphae are never found in pustules guarded from insects prior to mixing the nectar, it is evident that these are actually pycniospore nuclei.

The aecial primordium.-The development of the aecial primordium usually starts considerably before the first pycnia start discharging spores, but the degree of differentiation reached at the time of diploidization depends on the time that elapses between opening of the pycnia and mixing of the nectar. In nature the degree of differentiation is often very considerable, but if diploidization is effected very early, it may be slight. As a rule it is possible to distinguish the basal "fertile layer" and the outer "sterile layer," to use the terminology of the earlier writers. This outer tissue of very vacuolate cells has already served its purpose by thrusting aside and crushing the chlorenchyma cells, and it then gives up most of its nutritive material to the more active parts of the thallus and is destroyed when spore formation starts. It is possible for diploidization to start before this differentiation is evident, however, and this may partly account for the lack of agreement about the precise point of formation, in the young aecium, of the first dikaryon cells.

At the base of the primordium typical hyphal cells are seen, usually with slightly expanded nuclei. As we progress toward the apex (downward in the drawings), we find a more or less pseudoparenchymatous structure in which it is often impossible to tell which are the consecutive cells of a hypha. The first of these may have almost unexpanded nuclei, but those a little nearer the epidermis usually have completely expanded nuclei at the time when diploidization starts. Finally, directly beneath the epidermis, lie the "sterile" buffer cells whose nuclei are 


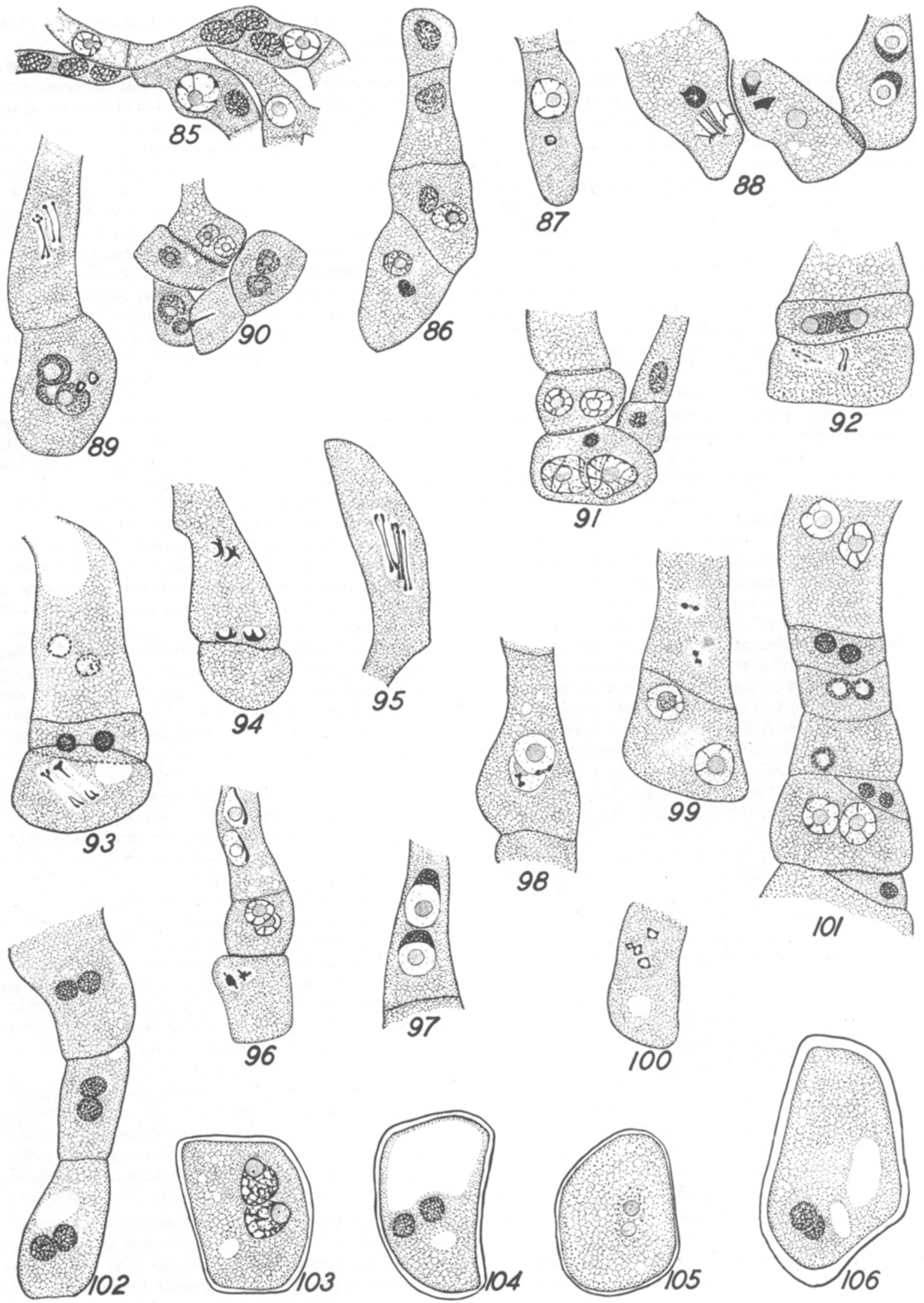


also nearly unexpanded. In a partly differentiated primordium the change of form of the nuclei can be studied. Figure 82 shows a group of cells from such a primordium of Puccinia Sorghi. The two dense nuclei at the left are completely unexpanded, though the hyaline zone surrounding each suggests that expansion might be about to start. At the right above is a partly expanded nucleus the chromatin of which is too evenly distributed for the boundary of the endosphere to be evident with the Feulgen stain. At the right below, nearest the leaf surface, is a nucleus in which the fully expanded form is being adopted. Here a large ectosphere has been delimited and the chromatin is passing out to its periphery along delicate protoplasmic strands. When the process is complete, most of the chromatin is usually very finely dispersed about the ectosphere membrane and may be only barely discernible with the Feulgen stain. This makes it very apparent that much more than chromatin is stained in the reticulum of the expanded nucleus when haematoxylin is used.

If diploidization is delayed beyond the time when these cells have become fully expanded, the primordium may continue to enlarge to some extent. This continued growth gives us an opportunity to observe the division of the expanded nucleus. The chromatin being all in the ectosphere, the division figure takes shape, not in a slightly enlarged endosphere, but in the ectosphere cavity. Figure 83 shows the chromosomes at about their maximum length, overlying the endosphere. Figure 84 shows a later prophase with the chromosomes partly contracted. The division of the expanded nucleus will be taken up in detail later, in connection with the formation of the aeciospores.

Diploidization.- If the nectar is mixed and compatible nuclei are introduced as soon as the pycnia open, diploidization may start before the nuclei with which they are to pair are fully expanded. When, on the other hand, mixing of the nectar is delayed for some time, the majority of nuclei in the base of the primordium become fully expanded. The state of the primordium at the time of diploidization can thus be seen to have some bearing on the ease with which the thallus nuclei can be distinguished from those that have been introduced, for the migrating nuclei are unexpanded. This point is clearly seen if figures $\mathbf{8 5}$ and 86 are compared. Figure 85 shows a group of cells at the base of a primordium of Puccinia Sorghi, fixed twenty-four hours after the nectar was mixed. In each cell there is one fully expanded thallus nucleus, with a clear green endosphere supported by a few delicate strands in the large ectosphere with almost all the chromatin disposed on its periphery. Sharply contrasting with these expanded nuclei are a number of evenly reticulate, smaller nuclei that take the Feulgen stain very strongly. Three of these are to be seen in the cell at the left; four, partly superimposed, are in the cell at the upper right, and there is one in the center cell below.

Figure 86 shows a single hypha from a primordium of Uromyces Lespedezae-procumbentis in which diploidization had progressed to about the same extent. The whole development of the pycnial and aecial stages of this rust seems to be much slower than that of $P$. Sorghi. The retardation includes not only the time between the opening of the first pycnia and the full differentiation of the primordia, but apparently even the time taken by the introduced nuclei in reaching the primordium. In no instance was any diploidization observed within twenty-four hours of mixing the nectar, while in $P$. Sorghi the minimum is apparently slightly under ten hours.

Fig. 85-106.-Fig. 85. Aecial primordium of $P$. Sorghi twenty-four hours after mixing nectar; numerous unexpanded introduced nuclei present, contrasting strongly with the expanded thallus nuclei. Feulgen. F. A. A.-Fig. 86. Hypha in partly diploidized aecium of $U$. Lespedezae-procumbentis. The terminal and subterminal cells each have one unexpanded and one almost fully expanded nucleus. Feulgen. F. A. A.-Fig. 87. Cell in P. Sorghi primordium twentyfour hours after mixing nectar; fully expanded thallus nucleus and small nucleus evidently in late prophase; the latter probably dividing to supply a nucleus for an adjacent cell. Feulgen. D. G.-Fig. 88. Conjugate divisions in partly diploidized aecium of $U$. Fabae; early prophase at right; later stage at center with ectosphere membrane broken down; at left, intermediate prophase stage, the four chromosomes in each nucleus still elongate and the two nuclei forming mirror images, while above there is a third nucleus in the cell. Feulgen. F. A. A.-Fig. 89. Same aecium as figure 88; terminal cell contains three expanded nuclei, while the fourth has apparently just divided to supply a nucleus to an adjacent cell. Feulgen. F. A. A.-Fig. 90. Nuclear migration at base of P. Sorghi aecium forty hours after mixing nectar. Feulgen. F. A. A.-Fig. 91. Chain of dikaryon cells in young $U$. Fabae aecium with extra, unexpanded nucleus in one cell and monokaryon hypha adjacent. Feulgen. F. A. A.-Fig. 92. Late anaphase in $U$. Fabue aeciospore mother-cell, the spindles not yet parallel. Feulgen. F. A. A.-Fig. 93. U. Fabae aeciospore column, showing early telophase in spore mother-cell; the spindles are parallel. Feulgen. F. A. A.-Fig. 94. Late telophase in $U$. Fabae basal cell, showing formation of endospheres of new nuclei. Feulgen. F. A. A.-Fig. 95. Early telophase in trinucleate basal cell of $U$. Fabae; this one originated deep in the primordium, but the majority are formed by equal-cell fusion of a dikaryon with a monokaryon cell. Feulgen. F. A. A.-Fig. 96. Eariy prophase in basal cell, and early anaphase in spore mother-cell of $P$. Sorghi. Feulgen. D. G.-Fig. 97. Early prophase in basal cell; same preparation as figure 96.-Fig. 98. Anaphase in P. Sorghi basal cell; endospheres and membranes of ectospheres visible at later stage than usual. Feulgen. D. G.-Fig. 99. Similar stage to last, but ectosphere membranes and one endosphere have disappeared; second endosphere is disintegrating. Same preparation as figure 98.-Fig. 100. End of anaphase in $P$. Sorghi basal cell; spindles not yet parallel. Feulgen. F. A. A.-Fig. 101. U. Fabae aeciospore chain, showing variation in nuclear form. Feulgen. F. A. A.-Fig. 102. Chain of columnar cells in $U$. Fabae aecium. Feulgen. F. A. A.-Fig. 103. U. Fabae aeciospore showing distinct granule, surrounded by "heller Hof," in each endosphere. Haematoxylin, with prolonged destaining. F. A. A.--Fig. 104. Peridial cell of U. Fabae. Haematoxylin. F. A. A.-Fig. 105. Peridial cell of $U$. Fabae with endospheres showing distinctly and chromatin indistinct. Granule visible in each endosphere. Buffer. F. A. A.-Fig. 106. Peridial cell of U. Fabae. Feulgen. F. A. A. 
Although there is little doubt which are the thallus and which the introduced nuclei in the two binucleate cells in this figure, it would have been difficult to make such a distinction for the other cells had they contained more than one nucleus; and, indeed, one cannot be sure that the nucleus in the top cell, which runs out of the section, is actually the thallus nucleus.

There is no sign in figures 85 and 86 of any partial dissolution of the septa, nor was this seen in any material of this stage. The unexpanded nucleus is evidently adapted to passing through minute openings. The septal pores, though not usually visible in the mycelium, can be seen to be about $0.15-0.20 \mu$ in diameter in the spores. Such an opening is probably ample for its passage, since that in the base of the haustorium is usually considerably narrower. In preparations steeped first in tannic acid and then in ferric chloride to give intensely stained walls, the septal pores in the older, vacuolate hyphae are seen to be filled by small plugs of undetermined composition. These are presumably destroyed or displaced by the migrating nuclei.

It will now be seen that the introduced nuclei can often be distinguished from the thallus nuclei in the ostiolar hyphae and at the base of the young aecium. It must be confessed, lowever, that the writer has not been able to recognize them in the vegetative hyphae leading from the pycnium to the primordium. Several factors combine to make this difficult. In the first place, the nuclei diploidizing a given primordium may often have entered through one of several pycnia. Secondly, the connecting hyphae do not run directly to the primordium, but meander so much that it is difficult to trace them from section to section. A third factor is the indistinctness, with the most useful cytological methods, of many of the septa; this makes it difficult to decide whether two nuclei are actually in the same cell or not. Finally there is the variability in appearance of the hyphal nuclei, which makes certain distinctions very difficult.

It is also suspected that the introduced nuclei pass through the connecting hyphae very rapidly, a behavior that would lessen the cliance of finding them. There is a strong possibility that these nuclei divide in the receptive hyphae, as is suggested by their distorted appearance and by the presence of two or three of them in a single hypha while adjacent hy phae contain none. Such divisions would tend to retard their movements. It is probable, however, that no such divisions occur in the journey from the pycnium to the edge of the primordium. Since the ground mycelium through which they pass is certainly not diploidized and no signs of such divisions have been found, there appears to be nothing to delay them.

When the edge of the primordium is reached, the nuclei evidently divide very freely. Divisions have occasionally been seen at the extreme base of primordia in which diploidization was just starting (fig. $62,63)$. It is not likely that the thallus nuclei in this position would undergo division. The point cannot be tested, however, for although early stages of the division might be found and might prove to belong to the unexpanded nuclei, it is quite possible that the thallus nuclei in this region would be only partly expanded. Divisions of the diploidizing nuclei at the extreme base of the primordia are also suggested by the finding of several in a single cell, while adjacent cells of the same hypha contain none (fig. 85). It is improbable that nuclei of the same strain, and therefore mutually repulsive, would complete their migration in such close association instead of becoming widely scattered.

Complete diploidization of the primordium is apparently effected in several ways. It is started by the introduced nuclei continuing their passage through the hyphae by which they entered and pairing up with the expanded nuclei of the enlarged cells toward their apices. Several cells of such a hypha may be diploidized (fig. 86), and those deep in the primordium then bud out and grow up beside those nearer the apex, so that all the spore mother-cells are cut off at approximately the same level. Thus one may partly account for the intertwining of the basal cells in the mature aecium that makes the origin of the dikaryon so difficult to determine. This could give complete diploidization only if large numbers of nuclei entered the primordium at many different points, for the primordium is made up of a number of hyphae that separate long before reaching it.

Actually, diploidization seems to start at one or two points only, and subsidiary methods therefore are needed. One method that is certainly adopted is the migration of extra nuclei from cells such as that at the upper right of figure 85 to cells in adjacent hyphae. Thus one of the introduced nuclei in the cell just referred to might very well migrate into the monokaryon cell directly below it. Such migrations would certainly be through narrow pores, for as long as the nuclei remain only partly expanded, they can easily revert to the unexpanded form, as when a haustorium is formed; and once the migration is completed, the point at which it occurred cannot be seen. These two methods of diploidization probably account for most of the nuclear migrations of the type first described by Blackman (1904).

A third probable method, the existence of which is difficult to prove or disprove, might be regarded as an extension of the one just described. If the cell to be diploidized was not actually touching the one from which the diploidizing nucleus was to be supplied, it is reasonable to suppose that a fusion papilla would be formed to bridge the gap. If, however, all the adjacent cells had already been diploidized, either all of these supernumerary nuclei would have to be functionless, or, instead of short papillae, one or more hyphal branches would have to be formed from the cell, and the introduced nuclei would have to move up in them to diploidize cells further from the base of the primordium. Two findings support this hypothesis. One is the occurrence of monokaryon cells with unexpanded nuclei (fig. 91) at about the level of the basal cells, after the start of 
diploidization when all the thallus nuclei in this region normally are expanded.

The second finding supporting the formation of such branches is the occurrence of equal-cell fusions such as Christman (1905) first described. There has been a tendency, since the discovery of the function of the pycniospores, to discredit either the reality or the importance of these fusions. Andrus (1931), in particular, has attempted to dismiss them as mere vegetative fusions that occur before diploidization. There can be little doubt, nevertheless, that diploidization does occur to some extent by this method in many rusts. In Uromyces Fabae these fusions are seen infrequently but rather regularly in the apical part of the basal cell region. This region is always filled by pseudoparenchyma tissue before diploidization starts, so that the vertically oriented fusion cells must be of later origin than the supposed vegetative fusions. That the fusions of vertically oriented cells are really functional is indicated by the occasional finding of fusions which result in the cutting of trinucleate spore mother-cells (fig. 95). Several examples, corresponding very closely to those described by Fromme (1912) for Melampsora Lini, have been seen in $U$. Fabae; it is sometimes possible to see that they have arisen by the fusion of a dikaryon hypha with a monokaryon. The evidence provided by such irregular fusions leaves no valid reason for denying the reality of the more typical ones.

It is probable that the nuclei of the introduced strain are often expanded by the time such fusions occur, and since the expanded nucleus does not seem to be so well adapted to passing through a small pore as the unexpanded one, one would expect either migration through a wide pore or complete fusion of the upper parts of the cells. The migration of an expanded nucleus through a relatively wide pore, about $0.6 \mu$ in diameter, is shown in figure 90. Whether such a pore would remain this size or whether it would gradually enlarge to give a typical fusion cell remains in doubt.

One other possible method of diploidization has been suggested by certain findings in the young aecium. Cells are occasionally found that contain an odd number of nuclei in various stages of development. Lamb (1935) seemed inclined to regard such discoveries as due to excessive application of pycniospores in artificial mixing of the nectar. The situation shown in figure 89 is not satisfactorily explained in this way. Here is a well-established basal cell with its nuclei in telophase. The cell shown below it is probably a second basal cell, since only two daughter nuclei of a spore mother-cell, namely those entering the new spore, become expanded. In this cell there are three expanded nuclei and what is evidently another nucleus in telophase. That so many nuclei should have migrated into this cell while only one remained in the cell through which they came seems improbable. The most feasible explanation is that this is a normal basal cell in which conjugate division had just taken place, and that one of the nuclei had been stimulated by the proximity of an ad- jacent monokaryon cell to undergo a further division, which would supply a nucleus to the latter. Similarly the small dense nucleus of the trinucleate terminal cell of figure 91 may have been formed by the division of one of the paired nuclei in this cell, providing for the diploidization of the adjacent monokaryon cell. In this instance, as was noted above, the unexpanded form of the nuclei in this monokaryon hypha suggests that they are of the introduced strain, so that the dividing nucleus would be of the thallus strain. The small nucleus seen in figure 87 is apparently in late prophase and is probably dividing in preparation for supplying a nucleus for an adjacent cell.

The division of one nucleus of a dikaryon cell without division of the second is not unprecedented. It occurs extensively during the progressive diploidization of a haploid hymenomycete mycelium, as shown by Buller (1930), and it presumably occurs to some extent in the diploidization of a haploid rust pustule by a diploid mycelium, as described by Brown (1932).

Sometimes, admittedly, nuclei are seen that have no obvious function. For example, in the left hand cell of figure 88 a compact nucleus is seen close to a pair of nuclei in prophase. A small projection of chromatin at one side of it suggests that it was either about to migrate at the time of fixation or had just done so, but its function is not clear, and it is possible that this actually is a superfluous nucleus.

The cytological evidence that the introduced nuclei divide freely to diploidize the primordium is strongly supported by the hybridization experiments of Newton, Johnson, and Brown (1930), who crossed various physiologic forms of Puccinia graminis Tritici. They found that if the pycnial nectar of several forms were mixed in a pycnium, different forms of the rust resulted from the different aecia, but that all the spores of a single aecium were usually identical. This highly important finding clearly suggests that the diploidizing nuclei in an aecium are typically the product of a single pycniospore. This does not necessarily mean that only one nucleus reaches the primordium. It is possible that the nuclei divide after entering the receptive hyphae and that two may reach the primordium by different routes. As already mentioned, diploidization has been seen to start in two different parts of the primordium. It would seem that the primordium's power of attraction is greatly diminished as soon as dipIoidization starts, so that only the practically simultaneous arrival of nuclei at different points can give rise to an aecium whose spores are not all genetically alike.

The aecium.-Conjugate division of the fully expanded nuclei starts in some of the basal cells and even spore mother-cells before diploidization of the primordium is complete. These conjugate divisions have been followed in some detail with the aid of the Feulgen method, which seems to be the only satisfactory means of staining the dividing nuclei without interference from the abundant ergastic material. 
The start of prophase is indicated by the chromatin becoming gathered to one side of the ectosphere, giving an effect reminiscent of the "bouquet" stage in the meiotic prophase of many animal cells. At first the nuclei tend to appear as identical images (fig. 96, 97). Later, the chromatin masses come to lie in adjacent positions, making the nuclei appear as mirror images, as is illustrated by the right hand cell of figure 88 and the middle cell of figure 92 . Intermediate stages, of course, are seen in which no relation is apparent. From the first appearance of the mirror-image condition there is considerable variation in the appearance of the various stages, because the time at which the ectosphere membrane and the endosphere break down varies widely. The chromatin of each nucleus next resolves itself into four threads with a maximum length about half that seen in the fusion nucleus; that is to say, the largest chromosomes attain a length of about $4 \mu$ and the shortest ones about $2 \mu$. In the left hand cell of figure 88 the situation is complicated by the presence of a third nucleus, but this cell offers a perfect example of the mirror-image effect already mentioned. The two nuclei are separated by a very fine film of cytoplasm. Just to either side of this film can be seen one of the long chromosomes. Beyond this, and approximately parallel to it in each nucleus, lies the second long chromosome, a little more widely separated from the first in the left hand nucleus than in the right. Toward the apical end of each nucleus is seen one of the short chromosomes, curved and lying at an angle to the long ones. The second short chromosome slightly overlaps the first and lies nearly parallel to the long ones. These mirror images clearly indicate that the dikaryon condition is preserved by two opposing forces acting on the two nuclei.

In the pair of nuclei just described the ectosphere has apparently disappeared, or, at any rate, is in the process of breaking down, and the endospheres have already disintegrated. Usually the endospheres persist until later in the division. The central cell in figure 88 shows a later prophase stage with the chromosome contraction in progress. The mirror-image effect is not clear, because the nuclei were not in the same focal plane. The endospheres are still intact, though one of them has drifted off into the cytoplasm after the dissolution of the ectosphere membrane. Metaphase figures are not easily recognized, because the spindle is not clearly shown with the Feulgen stain, but early anaphases are found without difficulty. If the ectosphere membrane is still intact, the spindle forms as a chord to it (fig. 98); but frequently it disappears before this stage, as in figure 99 , where one of the endospheres has also disappeared, while the last remnant of the other is visible.

The direction of the spindles, relative to each other and to the cell, seems at first to be a matter of chance, both in the basal cell and in the spore mother-cell (fig. 92). This may be true until early telophase (fig. 100); but usually by this stage the spindles lie side by side, parallel to the long axis of the basal cell (fig. 89) and diagonally in the spore mother-cell (fig. 93), where the intercalary cell is cut off somewhat to one side of the spore chain (fig. 101).

In late anaphase and early telophase we often see the effect (fig. 89, 92) that led Sappin-Trouffy to postulate a haploid chromosome number of two for the rusts. As the telophase progresses, the new endosphere is cut out (fig. 94) in the way described for the urediniospore, and the chromatin becomes distributed over its surface as in the top cell in figure 93. The pairs of nuclei resulting from the division of the basal cell both assume the expanded form; but of those resulting from the spore mother-cell division, only the spore nuclei become expanded, while most of the chromatin of the intercalary cell nuclei remains within the endosphere.

It is of interest to note (fig. 101) that the intercalary cells of a spore chain are generally cut off toward the same side. Possibly this has some function in the mechanism of spore discharge, but it seems more probable that it is connected in some way with the development of this unique method of spore production.

The spore nuclei are usually fully expanded by the time the spores are fully grown. The chromatin in the mature spore varies greatly in distinctness. Sometimes it is nearly all situated close to the ectosphere membrane and is not very evident, being, apparently, very finely dispersed. At other times it forms a distinct reticulum, but the heavy reticulum often obtained in haematoxylin preparations (fig. 103 ) is never duplicated with the Feulgen stain. This further indicates the misleading effects that may be obtained with dyes not truly specific for chromatin.

The germination of the aeciospores, including reversion of their nuclei to the unexpanded type, is identical with that already described for the urediniospores.

Here and there in the aecium of Uromyces Fabae one finds chains of columnar cells (fig. 102) with slightly expanded nuclei. No intercalary cells are formed in these chains, the cells remaining undivided after being cut off from the basal cells. 'These cells are thus the morphological equivalent of the spore mother-cells and of the peridial cells, the final division of which is also deleted. It should be noted that the basal cells from which these cells are cut off have the same type of nucleus. They may simply be an abnormality, but it is quite possible that they serve a purpose similar to the buffer cells in the uredinium and telium.

Finally, a few words should be said about the peridial cells, for they clearly illustrate the nuclear condition of the vegetative cells in general. They have nuclei that are actually slightly expanded, but this is not very apparent with some staining methods. To illustrate this point three lateral peridial cells of Uromyces Fabae are shown in figures 104, 105, and 106. Figure 104 was stained with haematoxylin and figure 106 with the Feulgen stain. It will be seen that the nuclei of both cells appear uniformly reticulate, no endosphere being discernible. Figure 105 was 
stained by the buffer method. The endospheres are very distinct and are about $1.25 \mu$ in diameter, while the nuclei of figures 104 and 106 are about $2.0 \mu$ in diameter. The outer part of each nucleus in figure 105 is virtually invisible because of the almost complete absence in these cells of the ergastic material on which the staining method depends. The abnormally small amount of this material present in the endospheres accounts for their invisibility in the haematoxylin preparation. It will be noticed that a small granule, surrounded by a "heller Hof," is visible in the endospheres in figures 103 and 105. This may possibly be a true nucleolus.

Discussion.- The changes in nuclear form here described for the rusts are decidedly unusual, and both the mechanisms involved and the causes underlying the changes are in need of explanation. It is to be hoped that further study in this group and, particularly, in other groups of the higher fungi will make the complexity of the rust nucleus more comprehensible. In the meantime the existence of these changes must be faced, and we must interpret them as best we can.

We must first consider how the whole of the chromosome substance can pass through the endosphere membrane, apparently without this membrane becoming in any way disorganized. The passage of chromatin through a membrane was first postulated in Hertwig's (1902) chromidial hypothesis. Cowdry (1924) discussed this hypothesis fully, pointing out that the term chromatin has all too often been applied to any substance that shows an affinity for basic dyes; but he concluded: ". . . . we are obliged to admit that it is by no means a rare occurrence for nuclear material to pass into the cytoplasm in large or small amounts." In the rusts we have a refinement of this situation. The nuclear material passes not into undifferentiated cytoplasm, but into an outer nuclear sphere, the ectosphere, newly formed from the cytoplasm. Modern microdissection investigations help to explain the situation. As Dr. Robert Chambers pointed out to the writer several years ago in connection with a different problem, a cytoplasmic or nuclear membrane, if violently pierced, will rupture; but if a needle or other object is gently introduced, no damage is done, and the membrane reforms behind it as it is withdrawn. The membrane, after all, is not to be regarded as a solid structure, but rather as a layer of oriented molecules, perhaps of lecithin or some related substance, at a liquid-liquid interface.

The problem of the functional necessity for the development of two distinct nuclear types is really more important than the mechanism involved in the change. One striking feature is that the unexpanded nuclear form occurs at every point of the life-cycle where the nuclei must pass through a very small pore. These stages are: the quadrinucleate basidium, the nuclei of which pass through the narrow tip of the sterigma; the basidiospore, which infects by the formation of a slender thread passing into an epidermal cell; the intracellular hypha resulting from basidiospore infection, the nuclei of which pass through a narrow pore into the intercellular space; haustorium formation, during which the nuclei enter the host cell through a narrow pore; the pycniospore, the nucleus of which passes into a receptive hypha; and finally the migrating pycniospore nucleus, which passes through the septal pores on its way to the primordium. It should further be noted that Pady's (1935b) illustrations of the persistent intracellular mycelium of Kunkelia nitens indicate what may be the same situation; the endosphere is evident only in the intercellular hyphae.

The only other points at which the nuclei are typically unexpanded are the brief interphase in the basidium, and the germination of the aeciospore and urediniospore. The germ-tubes of the aeciospores and urediniospores generally enter the host through the stomata, and their nuclei may divide several times before any haustoria are formed. The only recorded exception to this behavior is found in the aeciospores of Gymnoconia Peckiana. These were shown by Pady (1935a) to enter directly through the epidermal cells, but even here nuclear division usually preceded infection. The germ-pores of the aeciospores and urediniospores are always fairly large, and either type of nucleus can be formed, indifferently, after mitosis; the complicated process by which these nuclei discharge their endospheres does not, therefore, seem to have any advantage unless penetration of a host cell is to precede nuclear division. Then it would be functional, since apparently only the partly expanded nucleus, and not the fully expanded one, can revert to the unexpanded form by the method used in haustorium formation. Whether such a type of infection occurs in any existing species is doubtful.

In the fusion nucleus the prophase chromosomes attain such a length that the very large ectosphere might be essential here if these long chromosomes are necessary for the unrestricted formation of chiasmata. This, however, explains the very similar expansion in the aeciospores and urediniospores, and in the basal cells and spore mother-cells of all three stages, only if one assumes the evolution of all three types of sorus from a simple telium in which the spores were formed directly from hyphal cells without the intercalation of basal cells and spore mothercells.

Mechanical advantage may, conceivably, not be the sole explanation of the change in form of the nuclei. It will be noted that the expanded nucleus is found in those spores that must make extensive growth before renewing nutritive contact with the host. Aeciospores and urediniospores frequently produce germ-tubes exceeding $500 \mu$ in length, and their nuclei may divide several times before a host cell is entered. It is not known to what extent the germinating teliospore is dependent on the thallus to which it commonly remains attached. It appears from the work of Dietel (1915) that the water needed for germination is absorbed through the pedicel; but when the host tissue dies in the fall and the 
spore does not germinate till the following spring, it seems likely that all the food needed for the production of the basidium and spores is stored within the teliospore. Possibly the reserve nuclear material is largely stored within the nucleus. In sharp contrast to these spores are the basidiospore and pycniospore, which have unexpanded nuclei and also make little or no independent growth. The basidiospore puts out a short beak before passing directly into a host cell, and the pycniospore nucleus migrates into a receptive hypha of the thallus without any true growth occurring.

Even if food storage has no bearing upon nuclear structure, it certainly affects the staining reactions of the nuclei. A study of the staining reactions suggests a well-ordered economy in the protein metabolism of these highly specialized parasites. It has been observed, by using a number of staining methods, that there is a strong tendency for the rust nucleus to stain like the host nucleolus and for the rust cytoplasm to stain like the reticulum of the host nucleus. A lack of the necessary enzymes for the elaboration of proteins from simpler substances may partly explain the obligate parasitism of the rusts. These staining reactions, coupled with the close association of the haustorium with the host nucleus observed by most students of the group, suggest that the host enzymes may serve to break down the host proteins into amino-acids and that these, after absorption by the haustorium, are once more elaborated into proteins with the aid of the host's own enzymes. It is not to be assumed that the resulting proteins would be identical with those of the host, since it is well known that a slightly altered environment will materially affect the products of enzyme activity. It has been observed that both the nucleoprotein and the other stainable proteins of the nucleus appear, from the staining reactions, to be greatly diminished in the invaded areas of a rusted leaf.

It has already been stated that the nuclei of the basidiospores and pycniospores are scarcely distinguishable with the buffer stain, while those of the thallus and the other spore stages stain strongly. The unusual phenomenon of the nucleus taking an acid dye in preference to a basic one is explained by the fact that it is ergastic material, probably mainly proteins related to those found in the host nucleolus, that is stained rather than nucleoprotein. By checking with the Feulgen stain it can be seen that much of the nuclear substance stained with haematoxylin is also not nucleoprotein, and this is probably the same material. The basidiospore and pycniospore, as already pointed out, need little reserve material, and this accounts for their poor stainability. It is significant that the staining reactions of the ostiolar hyphae suggest that they contain more of this material than do the vegetative hyphae. This is evidently an economy on the part of the fungus, since any ergastic material in the hyphae can be retrieved for use elsewhere in the thallus, but most of that in the pycniospores must be lost because very few of them succeed in performing their function.
It is further to be remarked that the staining reactions show that much of the ergastic material in cells that have performed their function or that have only a mechanical function, such as the peridial cells, is removed for use in the more active cells.

Unfortunately very little detailed information is available on nuclear structure in the other groups of the higher fungi. A study of the published figures suggests that, with the exception of the fusion nucleus, the nuclei of the Hymenomycetes correspond to the unexpanded type of nucleus in the rusts. The writer has been fortunate in having the opportunity to examine many of Dr. Alexander H. Smith's preparations of various species of Mycena. It is evident that in this genus the paired nuclei in the young basidium are of the unexpanded type, that expansion starts just before or just after nuclear fusion, and that the expansion is a process of vacuolization essentially similar to that seen in the rusts.

The extensive cytological studies of the Ascomycetes have been directed along lines very different from those followed in the present investigation, and interpretation of the nuclear structure is generally impossible. Two recent papers, however, suggest points of interest. DeLameter (1937) shows the hyphal nucleus of Eidamella spinosa as a dark sphere about $1.5 \mu$ in diameter, in a liyaline zone about $2.0 \mu$ in diameter. This strongly suggests a similarity to the slightly expanded nucleus commonly found in the more active rust hyphae. His division figures indicate that division starts within this inner sphere rather than beside it in the outer cavity.

Colson (1938), in an extensive study of Phyllactinia corylea, maintains that the binucleate condition of the oogonium arises by division of the oogonium nucleus rather than by the entrance of the antheridial nucleus. It is difficult to secure an exact picture of these nuclei from her somewhat conventional figures, but one nucleus is large and has a large inner body; the other is much smaller and bears some resemblance to the unexpanded rust nucleus. A comparison of Colson's text figure 7 with the writer's figure 85 will emphasize this similarity. A point stressed by Colson was that the proportion of ascogenous cells that formed asci was so high as to preclude the possibility of nuclear migration and the existence of an irregular dikaryon; for the divisions in the ascogenous hyphae were not conjugate. By "conjugate" Colson evidently meant side by side rather than simultaneous. If, however, the divisions occur simultaneously but end to end as in the dikaryon hyphae of the rusts and if the nuclei subsequently slide past one another, the high proportion of compatible pairs could be obtained.

The mechanism by which the nuclei of the dikaryon cells maintain their relationship as pairs has always been a matter of interest. The mirror-image effect seen at prophase in the aeciospore basal cells clearly indicates the existence of two opposed and balancing forces. The mutual repulsion might well be due to similar charges on the two nuclei. Certainly it must be a force that will be increased as the 
nuclei are brought closer together; otherwise a balance could not be effected. It must also be due to some quality shared by all nuclei rather than to a difference between the nuclei of opposite strains; otherwise the balance seen in the occasional trinucleate cells could not be maintained. The mirror effect seen in figure 88 indicates that one of the forces acts upon a particular point in each chromosome. If the repulsive effect is due to equal charge, it is necessary only to assume that the charge is reduced at the time of fusion, rather than reversed, for the force of attraction will still be active. The occurrence of trinucleate cells is of additional interest, since it indicates that, even though the nuclei of a haploid thallus are alike in strain, there may be a difference in potency between sister nuclei. This may account for occasional findings that seem to represent the migration of a nucleus from a dikaryon cell to a monokaryon.

'The present observations seem to strengthen the view that the process of diploidization should be regarded as essentially similar to the process in the Hymenomycetes. The attempt to identify the structures involved as male and female organs leads to serious difficulties.

Lamb (1935) pointed out that, according to the view that the receptive hyphae are trichogynes leading to egg-cells, diploidization by the fusion of hyphae from intermingling monokaryon mycelia is fertilization of one female element by another. Ashworth $(1935 \mathrm{~b})$, discussing the stomatal hyphae accompanying the pycnia of Endophyllum Sempervivi, pointed out that connections could be traced between these hyphae and others leading to haustoria, whereas a trichogyne would be expected to connect only with a reproductive structure. The same investigator (1935a) described the occurrence of stomatal hyphae in different stages of several rusts. The finding of such hyphae accompanying the uredinia of Uromyces Fabae strengthens Ashworth's contention that they must not be regarded as specialized female structures, although it is possible that they occasionally serve as receptive hyphae.

In the species examined it seems certain that the ostiolar hyphae of the pycnium are the main, if not the only, places of entry for the pycniospore nuclei. This militates against the view that the pycnium is strictly a spermogonium.

It is evident that few introduced nuclei reach a primordium and that its diploidization is completed by these few dividing repeatedly to supply the required number. This fact and others gleaned from a study of the partly diploidized aecium show the behavior of the pycniospore nuclei to be very different from that of the nuclei of true spermatia, which do not divide repeatedly during their migration to the egg. They do not divide, after entering the egg, to supply spermatia for adjacent eggs; nor do we expect to find eggs arranged in rows, so that the spermatia have to pass through one in order to reach another. Finally, it is seen that the difference in size and form between the nuclei of the thallus and the introduced nuclei is not one of sex: if this were so, the nuclei of the basidiospores and haustoria would be male, and those of the aeciospores and urediniospores female.

When the differences in mode of life of the $\mathrm{Hy}$ menomycetes and the rusts are considered, it is no longer surprising that their diploidization processes should have developed along somewhat different lines. It must be remembered that the rust thallus soon virtually exhausts the available food material in the invaded part of the leaf or stem. This condition would impose a serious handicap upon the pycniospore if it had to grow through the leaf to the primordium. Lacking large quantities of reserve material, the pycniospore would have to establish connection immediately with the host or with the thallus. If the host cells are already exhausted, the logical solution of the difficulty is for receptive hyphae to be formed so that the pycniospore nucleus can enter the thallus without penetrating the host at all. The production of nectar in the pycnia for the attraction of insects that will distribute the spores entails the production of receptive hyphae where the insects will deposit these spores-namely, in other pycnia.

Bacteria and fungi cannot normally grow in the nectar. (That they do occasionally grow in diluted nectar if the weather is very moist may explain some reports of pycniospore germ-tubes growing down through the ostiole.) As Dr. A. H. R. Buller pointed out to the writer some time ago during a discussion of this subject, quite apart from the need of preventing mold growth in the nectar it is necessary that the pycniospores should be unable to grow in the nectar of their own pyenia. What could be more natural than that, having developed a method of entering the thallus without germinating, they should in time lose their power of germination? Parenthetically it may be suggested that some of the cases of slight germination reported for these spores may actually be merely the effect often seen when bacteria are placed in strongly hypotonic solutions: the protoplast swells to such an extent that it bulges out through the weakest part of the wall.

The invading nuclei do not diploidize the cells through which they pass. As Lamb pointed out, to do so would be waste of nuclear substance; for the future growth is localized in the aecium, and the remainder of the thallus serves only to conduct nutrient material to it.

The acceptance of the view here expressed necessitates the use of the terms "pycnium" and "pycniospore" in preference to "spermogonium" and "spermatium." It is unfortunate that Lamb, who strongly championed the same view, should have obscured his argument by clinging to the latter terms.

\section{SUMMARY}

By the use of new staining methods to supplement the usual procedures it has been shown that there are two distinct types of nucleus in the rusts, and the transition from one to the other has been elucidated. 
What is termed the unexpanded form is adopted in every part of the life-cycle where migration of the nucleus through a narrow pore is necessary. In the transformation of the unexpanded nucleus into the expanded, a new nuclear sphere, the ectosphere, is formed about the original nucleus. The chromatin passes through the original nuclear membrane and becomes distributed through the ectosphere, leaving the original nuclear sphere, or endosphere, completely devoid of it. The endosphere is the body commonly referred to by rust investigators as the nucleolus, but the use of this term is to be deprecated, since it is not homologous with the nucleolus of the higher plants. What is possibly a true nucleolus may sometimes be discerned within it.

The expanded nucleus is found in the aeciospores, urediniospores, and teliospores, and in their basal cells and spore mother-cells. This suggests the possibility of a common origin for these three spore forms.

With the aid of the Feulgen method, nuclear division has been followed in greater detail than was previously possible. In the unexpanded nucleus the spindle forms equatorially in the single nuclear sphere. In the expanded nucleus it forms beside the endosphere as a chord to the ectosphere membrane.

The nuclei of the mycelium usually have some of their chromatin outside the endosphere, but their division is essentially similar to that of the unexpanded nuclei.

Evidence has been secured that, in Puccinia Sorghi and Uromyces Fabae at least, the pycniospore nuclei enter the thallus through the ostiolar hyphae of the pycnium and that very few of these nuclei enter each primordium. Complete diploidization is accomplished by their repeated division after the primordium has been reached.

Preservation of the dikaryon condition by the operation of two opposed, balancing forces is indicated by the observation that in prophase the conjugate nuclei in the aecium tend to appear as mirror images of each other.

\section{University of Mictigan, \\ Ans Arior, Michigan}

\section{LITERATURE CITED}

Alien, R. F. 1930. A cytological study of heterothallism in Puccinia graminis. Jour. Agric. Res. 40: 585614.

——. 1931. Heterothallism in Puccinia triticina. Science $74: 462-463$.

- 1932. A cytological study of heterothallism in Puccinia coronata. Jour. Agric. Res. 45: 513-541.

. 1933a. Further cytological studies of heterothallism in Puccinia graminis. Jour. Agric. Res. 47: 1-16.

- 1933b. A cytological study of the teliospores, promycelia, and sporidia in Priccinia malvacearum. Phytopathology 23: 579-586.

- 1933c. The spermatia of corn rust, Puccinia Sorghi. Phytopathology 23: 923-925.

- 1934a. A cytological study of heterothallism in flax rust. Jour. Agric. Res. 49 : 765-791.

- 1934b. A cytological study of heterothallism in Puccinia Sorghi. Jour. Agric. Res. 49: 1047-1068.

-. 1935. A cytological study of Puccinia malvacearum from the sporidium to the teliospore. Jour. Agric. Res. 5I : 801-818.

Andrus, C. F. 1931. The mechanism of sex in Uromyces appendiculatus and $U$, vignae. Jour. Agric. Res, 42: 559-587.

Asirworti, D. 1931. Puccinia malvacearum in monosporidial culture. Trans. British Mycol. Soc. I6: $177-202$.

- 1935a. 'The receptive hyphae of the rust fungi. Annals Bot. 49: 95-108.

- 1935b. An experimental and cytological study of Endophyllum Sempervivi. Trans. British Mycol. Soc. $19: 240-258$.

Brackyas, V. H. 1904. On the fertilization, alternation of generations and general cytology of the Uredineae. Annals Bot. 18: 323-373.

C, Axn H. C. I. Fraser. 1906. Further studies on the sexuality of the Uredineae. Annals Bot. 20: 3548.

Bromie, H. J. 1931. The oidia of Coprinus lagopus and their relation with insects. Annals Bot. 45: 315-344.
1936. The occurrence and function of oidia in the Hymenomycetes. Amer. Jour. Bot. 23: 309-327.

Brown, A. M. 1932. Diploidization of haploid by diploid mycelium of Puccinia Helianthi Schw. Nature 130: 777.

-. 1935. A study of coalescing haploid pustules in Puccinia Helianthi. Phytopathology 25: 1085-1090.

Buller, A. H. R. 1930. The biological significance of conjugate nuclei in Coprinus lagopus and other $\mathrm{Hy}-$ menomycetes. Nature 126: 686-689.

- 1938. Fusions between flexuous hyphae and pycnidiospores in Puccinia graminis. Nature 141: 33-34.

Christman, A. H. 1905. Sexual reproduction in the rusts. Bot. Gaz. $39: 267-275$.

Crark, W. M. 1922. The determination of hydrogen ions. Second edition. Baltimore.

Colley, R. H. 1918. Pa rasitism, morphology, and cytology of Cronartium ribicola. Jour. Agric. Res. 15: 619-660.

Colsos, B. 1938. The cytology and development of Phyllactinia corylea Lév. Annals Bot. N. S. 2: 381402.

Cowdry, E. V. 1924. General cytology. Chicago.

Cratgie, J. H. 1927a. Experiments on sex in rust fungi. Nature 120: 116-117.

- $1927 \mathrm{~b}$. Discovery of the function of the pyenia of the rust fungi. Nature 120: 765-767.

- 1928. On the occurrence of pycnia and aecia in certain rust fungi. Phytopathology 18: 1005-1015.

- 1933. Union of pyeniospores and haploid hyphae in Puccinia Helianthi Schw. Nature 131: 25.

DeLAMETER, E. D. 1937. Eidamella spinosa Matruchet and Dassonville refound. Mycologia $29: 572-582$.

DE Tomast, J. A. 1936. Improving the technic of the Feulgen stain. Stain Technol. 11: 137-144.

Dietez, P. 1915. Versuche über die Keimungsbedingungen der Teleutosporen einiger Uredineen. III. Centralb. Bakt. 42: 698-705.

Duggar, B. M. 1909 . Fungous diseases of plants. Boston. 
Fron me, F. D. 1912. Sexual fusions and spore development of the flax rust. Bull. Torrey Bot. Club 39: 113-131.

-2. 1914. The morphology and cytology of the aecidium cup. Bot. Gaz. 58: 1-35.

HanNa, W. F. 1929. Nuclear association in the aecium of Puccinia graminis. Nature 124: 267 .

Hertwig, R. 1902. Die Protozoen und die Zelltheorie. Arch. Protistenk. 1: 1-40.

Horden, R. J., and R. A. Harper. 1903. Nuclear divisions and nuclear fusion in Coleosporium Sonchiarzensis Lév. Trans. Wisconsin Acad. Sci. 14: 63-82.

Huster, L. M. 1936. Molphology and ontogeny of the spermogonia of the Melampsoraceae. Jour. Arnold Arboretum 17: 115-152.

Jues, H. O. 1898. Die Kerntheilungen in den Basidien und die Phylogenie der Basidiomyceten. Jahrb. Wiss. Bot. 32: 361-388.

Kursayov, L. 1910. Zur Sexualitä der Rostpilze. Zeitschr. Bot. 2: 81-93.

-_- 1922. Recherches morphologiques et cytologiques sur les Urédinées. Bull. Soc. Nat. Moscon N. S. 31: 1-129.

LAмв, I. M. 1935. The initiation of the dikaryophase in Puccinia Phragmitis (Schum.) Körn. Annals Bot. $49: 403-438$.

Lil.i.je, R. D., and J. G. Pasternack. 1936. Romanowsky staining with buffered solutions. II. Current modification. Jour. Tech. Methods and Bull. Inst. Assoc. Med. Museums 15: $65-70$.

LrxwFons, T. 1924. Studien ueber den Entwicklungsverlauf bei einigen Rostpilzen aus zytologischen und anatomischen Gesichtpunkten. Svensk. Bot. Tidskr. 18: 1-84.

Mntgoren A, L. A. 1932. Feulgen's reaction and some of its applications for botanical material. Stain Technol. 7 : 9-16.
Moss, E. H. 1926. The uredo stage of the Pucciniastreae. Annals Bot. 40: 813-847.

__ 1929. The uredinia of Melampsora and Coleosporium. Mycologia 21: 79-83.

Naxlor, E. F. 1926. The hydrogen-ion concentration and the staining of sections of plant tissue. Amer. Jour. Bot. 13: 265-275.

Newtow, M., T. Johnsoy, AND A. M. Brown. 1930. A preliminary study on the hybridization of physiologic forms of Puccinia graminis Tritici. Sci, Agric. 10: $721-731$.

Orive, E. W. 1908. Sexual cell fusions and vegetative nuclear divisions in the rusts. Annals Bot. 22: 331360 .

Pady, S. M. 1935a. Aeciospore infection in Gymnoconia interstitialis by penetration of the cuticle. Phytopathology 25 : 453-474.

- 1935b. The rôle of intracellular mycelium in systemic infections of $R u b u s$ with the orange-rust. $\mathbf{M y -}$ cologia 27: 618-637.

Racicot, H. N., D. B. O. Savile, and I. L. Conners. 1938. Bacterial wilt and rot of potatoes-some suggestions for its detection, verification, and control. Amer. Potato Jour. 15: 312-318.

Rice, M. A. 1933. Reproduction in the rusts. Bull. 'Torrey Bot. Club 60: $23-54$.

Sapin-Troufry, M. 1896. Recherches histologiques sur la famille des Urédinées. Le Botaniste 5: $59-241$.

Scrmrrz, Fr. 1880. Untersuchungen über die Struktur des Protoplasmas und der Zellkerne der Pflanzenzelien. Sitz. Niederrh. Ges. Nat. Heik. Bonn 37: 159198. (Cited from Arthur, J. C. 1929. 'The plant rusts, New York.)

Semareys, C. S., axd P. N. Bhaduri. 1939. A technic for the differential staining of nucleoli and chromosomes. Stain Technol. 14: 1-5.

Welsfond, E. J. 1915. Nuclear migrations in Phragmidium violaceum. Annals Bot. 29 : $293-298$

\title{
A DEVELOPMENTAL ANALYSIS OF HETEROSIS IN LYCOPERSICON I. THE RELATION OF GROWTH RATE 'TO HE'TEROSIS ${ }^{1}$
}

\author{
William Gordon Whaley
}

Observations on the occurrence of hybrid vigor were a part of the first studies of plant hybridization. Kölreuter (1766), Knight (1799), Sagaret (1826), and Gärtner (1849), among the early investigators, recorded instances of great increases in size and yield in the progeny of certain crosses. Mendel (1865) reported that progeny secured in crossing two types of Pisum usually exceeded either parent strain in stem length and showed greater luxuriance generally. Nearly all the early papers

1 Received for publication April 24, 1939.

The writer wishes especially to express his appreciation to Professor E. W. Sinnott under whose direction this investigation was conducted. He is also indebted to the members of the Department of Botany of Cornell University and to Professor R. A. Emerson for the use of laboratory and field facilitics in the summer of 1938 and for much helpful criticism, and to Professors Eric Ashby and E. W. Lindstrom for their kindness in supplying seed material.

The second paper in this series will appear in a later issue of the American Journal of Botany. contain references to occurrence of greater vigor in the progeny of crosses, but no attempt was made to explain the phenomenon until many years later when Jost (1907), largely on the basis of Darwin's (1875, 1877) observations, suggested that the more vigorous growth of hybrids has as its cause the same stimulus which enables the egg to develop.

It was, however, some time after the discovery of Mendel's paper before attention was focused upon the immediate effects of cross-breeding. An understanding of Mendelian principles of inheritance resulted in several attempts to explain the cause of increased vigor in hybrid plants.

G. H. Shull (1908, 1909, 1910) and East (1908, 1909 ), working independently with maize, established the main facts upon which the first explanations were based. Both observed that self-fertilization in maize led to a decrease in size and vigor, the decrease becoming less and less in each generation until eventually a point was reached beyond which 